\title{
The Safety, Tolerability and Risks Associated with the Use of Newer Generation Antidepressant Drugs: A Critical Review of the Literature
}

\author{
André F. Carvalho ${ }^{a}$ Manu S. Sharma ${ }^{c}$ André R. Brunoni ${ }^{b}$ Eduard Vieta ${ }^{e}$ \\ Giovanni A. Favad, $f$ \\ ${ }^{a}$ Department of Clinical Medicine and Translational Psychiatry Research Group, Faculty of Medicine, Federal \\ University of Ceará, Fortaleza, and ${ }^{b}$ Interdisciplinary Center for Applied Neuromodulation, University Hospital \\ and Service of Interdisciplinary Neuromodulation, Department and Institute of Psychiatry, Laboratory of \\ Neurosciences (LIM-27), University of São Paulo, São Paulo, Brazil; 'Department of Psychiatry and Behavioral \\ Sciences, McGovern Medical School, The University of Texas Health Science Center at Houston (UTHealth), \\ Houston, Tex., and d Department of Psychiatry, University at Buffalo, Buffalo, N.Y., USA; eBipolar Disorders Program, \\ Institut d'Investigacions Biomédiques Agustí Pi Sunyer, CIBERSAM, University of Barcelona Hospital Clinic, \\ Barcelona, Spain; fDepartment of Psychiatry, University of Bologna, Bologna, Italy
}

\section{Key Words}

Antidepressant drugs · Selective serotonin reuptake inhibitors - Serotonin noradrenaline reuptake inhibitors . Tricyclic antidepressants - Side effects - Safety - Tolerability . Depression · latrogenic comorbidity · Adverse events

\begin{abstract}
Newer generation antidepressant drugs (ADs) are widely used as the first line of treatment for major depressive disorders and are considered to be safer than tricyclic agents. In this critical review, we evaluated the literature on adverse events, tolerability and safety of selective serotonin reuptake inhibitors, serotonin noradrenaline reuptake inhibitors, bupropion, mirtazapine, trazodone, agomelatine, vilazodone, levomilnacipran and vortioxetine. Several side effects are transient and may disappear after a few weeks following treatment initiation, but potentially serious adverse events may persist or ensue later. They encompass gastrointestinal symptoms (nausea, diarrhea, gastric bleeding, dyspepsia), hepatotoxicity, weight gain and metabolic abnormalities, cardiovascular disturbances (heart rate, QT interval prolon-
\end{abstract}

\section{KARGER}

www.karger.com/pps
E-Mail karger@karger.com gation, hypertension, orthostatic hypotension), genitourinary symptoms (urinary retention, incontinence), sexual dysfunction, hyponatremia, osteoporosis and risk of fractures, bleeding, central nervous system disturbances (lowering of seizure threshold, extrapyramidal side effects, cognitive disturbances), sweating, sleep disturbances, affective disturbances (apathy, switches, paradoxical effects), ophthalmic manifestations (glaucoma, cataract) and hyperprolactinemia. At times, such adverse events may persist after drug discontinuation, yielding iatrogenic comorbidity. Other areas of concern involve suicidality, safety in overdose, discontinuation syndromes, risks during pregnancy and breast feeding, as well as risk of malignancies. Thus, the rational selection of ADs should consider the potential benefits and risks, likelihood of responsiveness to the treatment option and vulnerability to adverse events. The findings of this review should alert the physician to carefully review the appropriateness of $A D$ prescription on an individual basis and to consider alternative treatments if available.

(c) 2016 S. Karger AG, Basel

A.F.C. and M.S.S. contributed equally as first authors of this article.
(C) 2016 S. Karger AG Basel

$0033-3190 / 16 / 0855-0270 \$ 39.50 / 0$ 


\section{Introduction}

Major depressive disorder (MDD) has increasingly been recognized as a major global public health issue due to the significant overall impact on mortality and morbidity, as well as high economic and human costs attached to it [1]. The WHO predicts that MDD will become the second leading cause of disability worldwide by the year 2030 [2]. In addition, an estimate indicates that antidepressants were the most frequently prescribed drugs taken by individuals aged 18-44 years between 2005 and 2008 in the USA, and were the third most common among all ages [3].

Depression is a chronic and recurring illness that may require lifelong treatment with different modalities. Compelling evidence indicates that a significant proportion of patients with MDD remain inadequately treated, especially in primary care settings $[4,5]$. Nonadherence and premature discontinuation of treatment are important factors that may significantly contribute to suboptimal outcomes [6]. Adverse effects associated with the use of antidepressant drugs (ADs) are some of the most common factors responsible for nonadherence and the discontinuation of treatment $[7,8]$. Studies have shown that up to $43 \%$ of patients with MDD may discontinue antidepressants due to treatment-emergent adverse effects [9].

The introduction of tricyclic antidepressants (TCAs) and monoamine oxidase inhibitors in the 1950s revolutionized the treatment of MDD. Since then, the search for more selective and possibly better tolerated ADs has continued. This movement of rational drug development gave birth to selective serotonin reuptake inhibitors (SSRIs). The ensuing years have witnessed SSRIs becoming the first-line drugs for the treatment of MDD among several other indications [10]. Following the marketing success of SSRIs, many newer generation antidepressants have gained approval as treatments for MDD, including but not limited to serotonin and noradrenaline reuptake inhibitors (e.g. venlafaxine, desvenlafaxine and duloxetine), bupropion (a noradrenaline and dopamine reuptake Inhibitor), mirtazapine (noradrenaline and selective serotonin antagonist) and trazodone (serotonin antagonist and reuptake inhibitor). With the exception of agomelatine (melatonin receptor agonist with $5-\mathrm{HT}_{2 \mathrm{C}}$ receptor antagonist properties), all other agents primarily act through the modulation of monoaminergic neurotransmission [11, 12]. The aforementioned drugs along with SSRIs are so-called newer generation antidepressants [13]. More recently, over the past 4 years, the US Food and Drugs Administration (FDA) has approved
Table 1. Main adverse events related to use of newer generation ADs

\begin{tabular}{cl}
\hline 1. & Gastrointestinal (nausea, vomiting, GI bleeding) \\
\hline 2. & $\begin{array}{l}\text { Hepatotoxicity and hypersensitivity reactions } \\
\text { (dermatologic and vascular manifestations) }\end{array}$ \\
\hline 3. & Weight gain and metabolic disturbances \\
\hline 4. & $\begin{array}{l}\text { Cardiovascular (QT interval prolongation, basal heart rate } \\
\text { and HRV, hypertension, orthostatic hypotension) }\end{array}$ \\
\hline 5. & Genitourinary (urinary retention, incontinence) \\
\hline 6. & Sexual dysfunction \\
\hline 7. & Hyponatremia \\
\hline 8. & Osteoporosis and fractures \\
\hline 9. & Bleeding \\
\hline 10. & $\begin{array}{l}\text { Central nervous system (seizure threshold, extrapyramidal } \\
\text { side effects, serotonin syndrome, headache, stroke) }\end{array}$ \\
\hline 11. & Sweating \\
\hline 12. & Sleep disturbances \\
\hline 13. & $\begin{array}{l}\text { Affective (apathy, switching into hypomania or mania, } \\
\text { paradoxical effects) }\end{array}$ \\
\hline 14. & Suicidality \\
\hline 15. & Safety in overdose \\
\hline 16. & Discontinuation syndromes \\
\hline 17. & Ophthalmic (glaucoma, cataract) \\
\hline 18. & Hyperprolactinemia \\
\hline 19. & Risk during pregnancy and breast feeding \\
\hline 20. & Risk of malignancies \\
\hline
\end{tabular}

three additional antidepressants for the treatment of MDD, namely vilazodone, levomilnacipran and vortioxetine [14].

Over the years, there has been a consistent effort to develop more efficacious ADs with better safety and tolerability profiles. There is no unequivocal evidence to support clinically significant differences in efficacy and tolerability among the various newer antidepressant agents and controversies remain in the literature [15-19]. In addition, in a meta-analysis that included 102 studies, no clinically significant differences were found in the efficacy of SSRIs and TCAs [10]. Differences in tolerability between TCAs and SSRIs appear to be modest [10, 2023]. In addition, concerns about safety and tolerability related to the long-term use of newer generation antidepressants have been raising in the literature $[24,25]$.

Here we critically review the side effects associated with the long-term use of newer generation antidepressants. In this review, we evaluate a wide range of untoward effects (table 1), although some rare treatmentemergent adverse reactions (mostly described in anecdotal case reports) are not discussed due to space limitations. A PubMed/MEDLINE database search was conducted 
with the search term 'antidepressive agents' [Mesh] crossreferenced with 'drug-related side effects and adverse reactions'[Mesh] OR 'specific side effect' (i.e. a separate targeted search for each side effect listed in table 1 was also conducted) from inception up until April 2, 2016. For this comprehensive review we considered for inclusion large-scale observational studies and randomized controlled trials (RCTs), as well as previous reviews, systematic reviews and meta-analyses, while case series and case reports were included if higher level evidence was not available. In this review, we primarily focus on data derived from populations with MDD.

\section{Gastrointestinal}

Serotonin plays a major regulatory role in the motor and sensory regulation of the gastrointestinal (GI) tract [26]. It is now well established that drugs with effects on serotonin receptors or serotonin levels can affect gastric motility [27]. Similarly, serotonergic agents that act on central $5-\mathrm{HT}_{3}$ receptors may lead to nausea and vomiting [28]. Some of the most frequently reported side effects associated with the use of SSRIs and serotonin noradrenaline reuptake inhibitors (SNRIs) include nausea, diarrhea, dyspepsia, GI bleeding and abdominal pain. Approximately half of all patients started on these agents experience GI side effects mainly in the first few days/ weeks following treatment initiation [29, 30]. Short-term SSRI use (7-28 days) is significantly associated with upper GI bleeding, suggesting that the same precautions that are used with nonsteroidal anti-inflammatory drugs and aspirin are appropriate [31]. Some studies have found nausea and vomiting to be one of the most common reasons for treatment discontinuation [32, 33]. Among SSRIs, fluvoxamine was associated with the highest rate of GI side effects, whereas escitalopram was less likely to cause GI side effects [34]. Most of these results were derived from observational studies and from case series submitted to regulatory authorities. Thus, the comparative incidence rates of nausea across different antidepressant agents remain incompletely elucidated. A meta-analysis of adverse reactions reported during clinical trials indicated that when compared to SSRIs and duloxetine, the use of venlafaxine was associated with higher rates of nausea and vomiting, while sertraline appeared to be associated with a higher incidence of diarrhea when compared to other SSRIs and venlafaxine [35]. The extended-release formulations of venlafaxine and paroxetine may be associated with lower rates of nausea than their immediate- release formulations [36]. However, a recent meta-analysis did not find significant differences in the rate of adverse events (including nausea) between immediate versus extended-release venlafaxine [37]. The data for the most recently approved antidepressant agents (i.e. vortioxetine, vilazodone and levomilnacipran) remain limited. Nevertheless, similarly to other antidepressant agents, nausea was one of the most frequently reported side effects [38-40].

\section{Hepatotoxicity and Hypersensitivity Reactions}

The incidence of drug-induced liver toxicity among patients taking SSRIs and SNRIs ranges from 0.5 to $1 \%$ and this risk seems to be more elevated among patients exposed to nefazodone, bupropion, agomelatine and duloxetine [41]. The elevation of alanine aminotransferase levels above 3 times the upper normal limit provides an indication (i.e. a 'red flag') of clinically significant druginduced liver injury (DILI) [41]. Liver toxicity may occur within days to about 6 months after antidepressant treatment initiation. It is noteworthy that symptoms of liver toxicity and neurovegetative manifestations of MDD including fatigue and loss of appetite may overlap. Antidepressant-induced liver injury is generally dose-dependent, with higher doses being more likely to cause liver injury [42]. In addition, polypharmacy, especially with the concomitant administration of multiple compounds metabolized by the same CYP450 isoenzymes, is an important risk factor for DILI. For example, the concomitant use of duloxetine plus trazodone, duloxetine plus fluoxetine, duloxetine plus mirtazapine, and venlafaxine plus trazodone have been associated with severe liver injury [for a review, see 41].

Two main mechanisms may be involved in antidepressant-induced liver toxicity, namely a metabolic component and/or an immuno-allergic pathway. A hypersensitivity syndrome with fever and rash as clinical manifestations, as well as with autoantibodies and eosinophilia, and a short latency period (1-6 weeks) point to a predominantly immunoallergic pathophysiological mechanism [43], whereas a lack of hypersensitivity syndrome and a longer latency period (i.e. 1 month to 1 year) points to an idiosyncratic metabolic mechanism [44].

Citalopram and escitalopram have been considered the safest among the SSRIs with respect to potential for liver injury [41]. On the other hand, the risk of liver toxicity for nefazodone was so high that it was subsequently withdrawn from the market [45]. A recent systematic review found 
that the incidence of agomelatine-induced liver injury was as high as $4.6 \%$ and the risk of liver injury appeared to be dose dependent [46]. Case reports of life-threatening liver toxicity, in some cases requiring liver transplantation, have been described in the literature for nefazodone, duloxetine, venlafaxine and agomelatine [41]. Thus, clinicians should regularly monitor liver function while treating patients with antidepressants, particularly if using agomelatine and duloxetine. Baseline liver function tests should be tested prior to treatment initiation and thereafter following dose increments. Special care should be taken when treating patients with preexisting liver disease and, if possible, drugs with low liver toxicity (for example, citalopram and escitalopram) should be used in these patients [41].

Cutaneous adverse drug reactions may also occur among individuals using SSRIs; the evidence for these adverse skin reactions comes from prospective and retrospective cohort studies [47]. Most commonly, SSRIs have been associated with petechiae and ecchymosis, which occur secondarily to the effects SSRIs on platelet aggregation [48]. Some individuals can develop skin reactions on the face, neck and dorsum of the hands secondary to excessive exposure to sunlight $[47,48]$. The long-term use of SSRIs can be linked to hyperpigmentation of hair, skin and nails [47]. Another adverse effect is alopecia which is most commonly seen with the use of fluvoxamine [47, 49]. In addition, SNRIs have not been associated with major cutaneous adverse reactions apart from hyperhidrosis, which is discussed below [47]. Finally, the use of mirtazapine has been associated with rash, acne, exfoliative dermatitis and alopecia [47].

\section{Weight Gain and Metabolic Disturbances}

Weight gain during antidepressant therapy may occur during both acute and maintenance phases of treatment [50]. In addition, weight gain may be a sign of improvement or even a residual symptom of atypical depression [50]. Notwithstanding the complexity of the clinical scenario, compelling evidence indicates that the use of most antidepressants may increase weight in a significant proportion of patients [51]. The interaction of several mechanisms may contribute to antidepressant-induced weight gain, including but not limited to: (i) the action on specific neuroreceptors (e.g. antagonism to histaminergic $\mathrm{H} 1$ receptors and serotonin $5-\mathrm{HT}_{2 \mathrm{C}}$ receptors); (ii) a decrease in caloric expenditure due to the sedative effects of certain antidepressants; (iii) a shift in food preference, and (iv) dry mouth/throat may lead to an increased intake of caloric beverages [50,52]. Recently, it has been suggested that an increase in exposure to antidepressants via a multitude of mechanisms may be a driving force for the obesity pandemic [53].

Despite the fact that SSRI use has been associated with weight loss during acute treatment, several studies have indicated that long-term use (more than 6 months) is associated with weight gain [53]. In addition, evidence indicates that paroxetine may be the worst SSRI when it comes to weight gain $[51,52]$. In addition, a prospective population-based study indicates that the use of ADs may be associated with a higher risk of obesity [54]; it is possible that the oppositional model of tolerance may also apply to the emergence of weight gain following longterm $\mathrm{AD}$ treatment [55]. According to this model, continued drug treatment may recruit processes that oppose the initial acute effects [55].

Mirtazapine is the newer generation antidepressant most consistently associated with significant weight gain in the initial phases of treatment [51]. Some studies showed a paradoxical reduction in weight gain in doses ranging from 75 to $90 \mathrm{mg}$ and above [56]. Unlike mirtazapine, the use of bupropion may promote weight loss in a subgroup of patients who may lose up to $12.9 \%$ of their body weight after 24 weeks of treatment [57]. In addition, despite its structural similarities to sibutramine, significant weight change has not been associated with the use of venlafaxine [58]. The limited evidence to date suggests that vortioxetine and vilazodone do not promote significant weight gain in patients with $\operatorname{MDD}[59,60]$.

Some antidepressants that may promote weight gain (e.g. TCAs and mirtazapine) may also impact on serum lipid parameters, whereas a direct weight-independent effect on serum cholesterol has not been consistently reported $[61,62]$. The association between antidepressant use and incident diabetes mellitus (DM) remains inconclusive [62]. Some reports point to a higher risk of DM [63-65] whereas others do not [66, 67]; however, a recent systematic review and meta-analysis found that antidepressants (mainly SSRIs and TCAs) increase the risk of $\mathrm{DM}(\mathrm{OR}=1.5,95 \%$ CI $1.08-2.10 ; \mathrm{HR}=1.19,95 \% \mathrm{CI}$ 1.08-1.32) [68]. As the included studies were observational, this association may not be causal [69].

\section{Cardiovascular}

A substantial body of evidence indicates that the cardiovascular safety profile of newer generation antidepressants is significantly improved compared to the TCAs, 
with a lower degree of anticholinergic side effects along with better safety in the setting of acute overdose. Most SSRIs have been associated with a reduction in basal heart rate [70-72], even though a recent large study has found the opposite (an increase in heart rate associated with the use of SSRIs) [73]. On the contrary, the use of SNRIs (e.g. venlafaxine and duloxetine) has been associated with an increase in basal heart rate $[25,74]$. In addition, SSRIs and SNRIs may promote a decrement in heart rate variability (HRV) $[73,75]$. Although the impact of the effects of antidepressants on HRV remains to be established, data indicate that a lower HRV is a significant predictor of incident cardiovascular events [76]. Levomilnacipran (perhaps as a consequence of its noradrenergic effects) promotes increments in basal heart rate, whereas adequate data are missing as to the cardiovascular effects related to the use of vilazodone and vortioxetine [40,77].

The effects of SSRIs on QT interval prolongation have also emerged as a significant source of concern [78]. The QT interval is defined as the period elapsed between the onset of a Q wave and the end of a T wave in the electrocardiogram. The QT interval can vary with heart rate and becomes shorter as the heart rate increases. The QTc refers to the corrected QT interval (i.e. after adjustment to basal heart rate). Among the SSRIs, citalopram may cause a clinically significant increase in the QTc interval and has also been associated with cases of torsades de pointes [79]. A few case reports have suggested an association whereby the use of fluoxetine and sertraline may lead to QTc prolongation in individuals with preexiting risk factors for QTc prolongation. Paroxetine can be considered the least likely SSRI to cause QTc prolongation [79]. A recent meta-analysis also confirmed that among SSRIs, citalopram appears to be the agent most significantly associated with QTc prolongation [80].

Venlafaxine use has been associated with clinically significant increases in diastolic blood pressure of up to 15 $\mathrm{mm} \mathrm{Hg}$ from baseline. This risk was lower among individuals receiving doses of less than $200 \mathrm{mg}$ daily [25, 81]. Duloxetine may also increase blood pressure [82] and levomilnacipran may increase both systolic and diastolic blood pressure, although the magnitude of the effect seems to be small and its clinical significance is yet to be determined [38]. The SNRIs have not been consistently associated with clinically significant cardiac conduction defects or arrhythmias [25].

Studies investigating the risk of orthostatic hypotension secondary to the use of ADs have employed different definitions of orthostatic hypotension ranging from clinical symptoms of postural dizziness to predefined pos- tural changes in blood pressure and heart rate. It is well established that TCAs may cause orthostatic hypotension due to their well-known antagonistic $\alpha_{1}$-adrenergic receptor activity [83, 84]. The main mechanisms associated with SSRI-induced orthostatic hypotension remain unknown. Postural hypotension associated with the use of SSRIs is most commonly observed in elderly populations [83]. Paroxetine seems to be the SSRI most frequently associated with orthostatic hypotension at least partly due to its anticholinergic effects [85]. This increased anticholinergic effect may help explain the increased risk of orthostatic hypotension especially in the elderly [86]. Similarly, fluoxetine use has also been associated with an increased incidence of orthostatic hypotension among the elderly [87].

Among SNRIs, some studies suggest that venlafaxine may cause orthostatic hypotension in more than $50 \%$ of patients aged over 60 years, most likely secondary to its strong noradrenergic action [88]. Although there have been no formal studies, a few case reports suggest a risk of orthostatic hypotension also for patients who were prescribed duloxetine [85]. In addition, mirtazapine may cause orthostatic hypotension in up to $7 \%$ of patients [89].

\section{Genitourinary}

Urinary retention secondary to the use of SSRIs appears to be a rather rare event and is supported only by case reports [90]. In most cases, SSRIs have been implicated only when used in combination with benzodiazepines and/or antipsychotics. These case reports have particularly concerned fluvoxamine, while fewer studies have implicated fluoxetine [90]. SSRIs can cause urinary retention by acting on central micturition pathways. Serotonin may increase the central sympathetic outflow leading to urinary storage, and at the same time inhibits parasympathetic flow, which affects voiding [91]. On the other hand, SNRIs may cause urinary retention via actions on $\alpha_{1}$-adrenoreceptors. There have been case reports which have shown that the use of venlafaxine and reboxetine has led to cases of urinary retention [25]. There have also been a few reports to suggest that venlafaxine can also cause urinary incontinence. Even though the exact underlying mechanism is unknown, the action of venlafaxine on $5-\mathrm{HT}_{4}$ receptors appears to cause incontinence [92]. Likewise, duloxetine appears to be associated with both urinary retention and hesitancy [25]. 
A large retrospective study found that the relative risk of incontinence associated with the use of SSRIs was approximately 1.61 , with sertraline having the highest relative risk. However, causal inferences linking SSRIs and urinary incontinence remain to be established [93]. It is noteworthy that most cases which reported urinary incontinence or retention related to the use of either SSRIs or SNRIs involved individuals who were on a wide variety of drugs, which could have contributed to the reported incontinence or retention.

\section{Sexual Dysfunction}

The prevalence of sexual dysfunction is considerably higher among individuals with MDD compared to the general population. For instance, loss of libido has been reported to affect $25-75 \%$ of patients with MDD, and its prevalence may correlate with the severity of depressive symptoms [94], while a decrease in desire and arousal may affect $>50 \%$ of patients who have received a diagnosis of MDD [95]. In addition, a significant body of data shows that antidepressants may differentially affect sexual function in multiple aspects, leading to reductions in libido, arousal dysfunction (erection in males and vaginal lubrication in females) and orgasmic dysfunctions [95, 96].

These side effects are some of the most underreported adverse effects associated with the use of antidepressants, and a growing body of evidence indicates that clinicians should actively monitor for such side effects. The use of validated instruments to assess sexual dysfunction seems to enhance the identification and quantification of these adverse events [97]. These adverse reactions are a major contributor of treatment discontinuation and lack of adherence $[98,99]$. Several mechanisms may contribute to antidepressant-induced sexual dysfunction, including but not limited to psychosocial factors and comorbid medical diseases, as well as the use of other medications that may affect sexual function [95]. According to one hypothesis, the serotonergic action of SSRIs and SNRIs reduces dopaminergic transmission in the mesolimbic area, which in turn is known to regulate orgasm and sexual desire [100].

The prevalence of sexual side effects can be as high as 50-70\% among individuals taking SSRIs. These effects are reduced or absent among individuals taking medications with a predominant effect on dopamine or noradrenaline reuptake (e.g. bupropion). All SSRIs along with SNRIs have been shown to have significant sexual side effects. There are minor individual variations among these drugs but, according to a recent network meta-analysis, these differences were not statistically significant [101]. Bupropion appears to have a favorable tolerability profile with regards to sexual side effects [102]. In fact, it has established itself as the drug of choice for patients who have experienced sexual side effects from other antidepressants [103]. In addition, mirtazapine and agomelatine have been associated with lower risks of sexual side effects [104]. Preliminary data suggest that vortioxetine and vilazodone might have some advantage over SSRIs with regards to sexual side effects [59, 60, 105].

During the course of antidepressant therapy, clinicians should continuously monitor for the possibility of sexual side effects. Several strategies have been investigated for the management of sexual dysfunction associated with antidepressants [for a review, see 106]. For example, clinicians may attempt a switch to an antidepressant with a lower rate of sexual dysfunction. In addition, tricyclic antidepressant agents have long been implicated in the emergence of sexual side effects. Clomipramine, imipramine and amitryptiline are particularly troublesome, whereas nortriptyline may be less so [107, 108].

Some antidotes (e.g. bupropion) have been proposed as effective strategies for a subgroup of patients [109]. The use of type 5 phosphodiesterase inhibitors (e.g. sildenafil, tadalafil and vardenafil) may also alleviate antidepressant-induced erectile dysfunction [106]. Finally, it is worth mentioning that for a small group of patients sexual dysfunction may either persist after treatment discontinuation or be a transitory phenomenon during $\mathrm{AD}$ treatment [110].

\section{Hyponatremia}

Most of the evidence pointing towards an increased risk of hyponatremia with the use of antidepressant medications is based on multiple case reports and a few observational studies. The SSRIs and venlafaxine appear to be the antidepressants most commonly associated with hyponatremia [111]. Among the SSRIs, the incidence of hyponatremia varies based on the definition of hyponatremia used. For studies which defined hyponatremia as serum sodium levels $<135 \mathrm{mmol} / \mathrm{l}$, the incidence ranged from 9 to $40 \%$. The incidence decreased to $0.06-2.6 \%$ when hyponatremia was defined as serum sodium levels $<130 \mathrm{mmol} / \mathrm{l}$ [111]. There were no consistent difference in the incidence of hyponatremia among different SSRI 
members, but available data indicate that the incidence could be slightly higher for fluoxetine, citalopram and escitalopram, whereas incidence rates may be lower for paroxetine and sertraline [112-114]. The data looking at the risk of hyponatremia associated with the use of SNRIs are even more limited [111]. Most studies have found incidence rates of hyponatremia comparable to the ones reported for SSRIs. Incidence figures for mirtazapine and TCAs appear to be lower [111].

The risk of hyponatremia is significantly higher in elderly patients and among individuals using diuretics. The mechanisms of SSRI-induced hyponatremia remain incompletely elucidated, but these agents can act by either increasing the release of antidiuretic hormone $(\mathrm{ADH})$ or increasing the sensitivity to ADH resulting in a clinical picture similar to the syndrome of inappropriate secretion of $\mathrm{ADH}[62,111]$. The discontinuation of the antidepressant, fluid restriction and diuresis are possible measures that can be taken to treat antidepressant-induced hyponatremia [115].

\section{Osteoporosis and Fractures}

Multiple studies and a subsequent meta-analysis have associated depression with an increased risk of fractures and a reduction in bone density among patients [116]. Furthermore, a recent meta-analysis of 10 studies found a significant reduction in lumbar and hip mineral density in adults aged 60 years and older [117]. This reduction in bone density and a metabolic state which favors bone resorption has been attributed to a complex interplay between the hypothalamic-pituitary-adrenal (HPA) axis and inflammation [118]. Patients with depression tend to have increased secretion of cortisol and also display elevation in markers of inflammation, especially, IL-1, IL-6 and TNF- $\alpha$ (which in turn can also increase cortisol secretion) [119].

The use of SSRIs has been associated with a reduction in bone mineral density (BMD) and a consistent higher risk of fractures [118]. A recent meta-analysis found that the relative risk of fractures associated with the use of SSRIs was 1.72 (95\% CI 1.51-1.95), and this risk could not be accounted for by variations in BMD [120]. In a largescale case-control study, among the SSRIs, high doses of citalopram, fluoxetine, paroxetine and sertraline carried an odds ratio of 1.98 (95\% CI 1.82-2.16) with respect to risk of fractures. The same analysis did not find significant increase in the risk of fractures related to the use of mirtazapine, venlafaxine and reboxetine [121].
In summary, MDD and the use of antidepressants have been individually associated with an increased risk of fractures and a reduction in BMD. However, based on extant data it seems difficult to precisely determine whether these observations are due to an exposure to antidepressants, a result of the disease process or a combination of both.

\section{Bleeding}

All serotonergic antidepressants have been associated with an increased risk of bleeding [122]. The most likely mechanism responsible for these adverse reactions is a reduction of serotonin reuptake by platelets, although other mechanisms have also been implicated $[122,123]$. In fact, serotonin influences platelet aggregation induced by adenosine diphosphate, epinephrine and collagen [124]. Among the SSRIs, fluoxetine, paroxetine and sertraline have been related to a higher risk of platelet dysfunction when compared to other SSRIs [122]. Among other antidepressants, venlafaxine and mirtazapine also have been associated with an increased risk of bleeding [122]. SSRIs have been associated with an increased risk of bleeding during surgical procedures [125]. The risk of bleeding appears to be higher with concomitant use of nonsteroidal anti-inflammatory drugs (NSAIDs) including aspirin, preexisting platelet dysfunction, or a concomitant use of heparin [124]. A recent observational cohort study pointed towards an increased risk of intracranial bleeds in patients concomitantly using NSAIDs and SSRIs [126].

The use of SSRIs could be associated with an increased risk of upper GI bleeding [31, 127]. The overall risks are substantially higher among individuals on concomitant use of nonsteroidal anti-inflammatory agents [127, 128]. The association between the use of SNRIs and upper GI bleeding is less compelling with inconsistent results across studies [129-131]. The role of proton pump inhibitors against this increased risk of GI bleeding when used with SSRIs has not been firmly established $[15,130$, $132,133]$.

\section{Central Nervous System}

ADs can lower the seizure threshold; the epileptogenic potential is higher for TCAs than for bupropion, which is still contraindicated for individuals with seizure disorders [134]. Over the years many case reports have associated extrapyramidal symptoms (EPS) with the use of an- 
tidepressants. All kinds of EPS are seen in patients taking antidepressants, but akathisia appears to be the most common presentation followed by dystonic reactions, parkinsonian movements and tardive dyskinesia [135]. Akathisia appears to be more common in younger patients as compared with the other EPS symptoms [136]. Among antidepressants, SSRIs have the highest number of case reports of EPS [137, 138]. The mechanisms responsible for EPS may be related to excessive levels of serotonin, which may disrupt dopaminergic neurons in the nigrostriatal and tuberoinfundibular pathways [139]. The incidence of EPS appears to be highest among patients taking duloxetine, followed by sertraline, escitalopram, paroxetine, fluoxetine, bupropion and citalopram in decreasing order of incidence [140]. The elderly and individuals who carry the $\mathrm{A} 1$ allele of the dopamine $\mathrm{D}_{2}$ receptor (DRD2) gene Taq1A polymorphism were at increased risk of developing EPS with the use of SSRIs [141]. In addition, a few case reports of neuroleptic malignant syndrome have been attributed to the use of antidepressants, and even to the withdrawal of SSRIs [134, 142].

The widespread use of SSRIs may result in the socalled serotonin syndrome, which is a highly heterogeneous and life-threatening condition characterized by a triad of mental-status changes, autonomic hyperactivity and neuromuscular abnormalities, but not all of these manifestations are universally present in patients presenting with this disorder [143]. The concomitant use of SSRIs and monoamine oxidase inhibitors may pose a significant risk [144], while the serotonin syndrome may occur in up to $16 \%$ of individuals who overdose on SSRIs [145]. The recognition of milder cases of this syndrome may be challenging and, although the diagnosis must be made on clinical grounds, the assay of urinary levels of serotonin may prove to be useful [146].

The achievement of cognitive remission has emerged as a novel yet unmet objective of AD treatment [147]. Antidepressants may have a small beneficial effect upon certain cognitive domains (e.g. delayed recall and psychomotor speed) [148]. However, the use of antidepressants may also lead to cognitive side effects [149]. For example, in one study a significant impairment of executive function was related to the use of SSRIs [150]. In addition, the use of antidepressants was associated with inattentiveness, forgetfulness, word-finding difficulty and mental slowing in depressed individuals reaching partial or full remission [151].

Headache was one of the most common side effects associated with the use of antidepressants in a large retrospective cohort of adolescents and adults [152]. Finally, a meta-analysis of observational studies indicated that the use of SSRIs could be associated with a $40 \%$ increased risk of stroke [153]. However, this association was significant only in older age groups. In addition, a recent cohort study conducted in UK primary care settings did not confirm this association [154].

\section{Sweating}

Sweating is a compensatory mechanism used by the body to keep its temperature within a physiological range. Excessive sweating is an uncomfortable and often embarrassing side effect of antidepressant medications. The action of TCAs on muscarinic receptors may lead to excessive sweating in approximately $14 \%$ of the patients who take them [155]. Among the newer antidepressants, bupropion and venlafaxine have been more frequently associated with excessive sweating, while fluvoxamine and trazodone may be associated with lower incidence rates [156]. Most studies indicate that approximately $10 \%$ of patients on SSRIs may develop excessive sweating, although the incidence may be higher for paroxetine [25, 156]. The use of benztropine and cyproheptadine for the alleviation of antidepressant-induced sweating has been attempted with success, although the quality of the evidence is limited [156-158].

\section{Sleep Disturbances}

Sleep disturbances are one of the hallmark manifestations of depressive illnesses. Studies have shown that patients suffering from depression have reduced rapid eye movement (REM) latency and a reduction in the nonREM phases in the first sleep cycle [159]. However, there are significant sources of heterogeneity across studies [160]. The SSRIs and venlafaxine are associated with increased REM sleep latency and a reduction in the overall time spent in the REM phase while sleeping. These effects on REM sleep are mostly associated with the initial days/ weeks of treatment, and may return to baseline levels after 8 weeks of treatment. A rebound in REM sleep can be measured upon discontinuation of SSRIs. These effects on REM sleep could be due to an increase in synaptic serotonin levels. Mirtazapine can increase latency to REM sleep. In addition, trazodone and mirtazapine have been associated with improving sleep continuity in patients with MDD [161]. Evidence indicates that a subgroup of patients may intensify dreaming and report troublesome 
nightmares when they begin taking SSRIs or SNRIs, and even more so when they discontinue their use [162].

In addition, SSRIs and venlafaxine may cause and exacerbate restless leg syndrome. Among the newer antidepressants, mirtazapine followed by paroxetine and sertraline have been associated with the highest incidence of restless leg syndrome [163]. Furthermore, some case reports have related the use of venlafaxine to the emergence of periodic limb movement disorder [164]. Unlike other antidepressants, bupropion has been known to ameliorate the symptoms of restless leg syndrome [165].

\section{Affective Disturbances}

Many patients taking SSRIs have reported experiencing emotional blunting. They often describe their emotions as being 'damped down' or 'toned down', while some patients refer to a feeling of being in 'limbo' and just 'not caring' about issues that were significant to them before [166]. Evidence indicates that these adverse affective manifestations may persist even after the symptoms of depression have improved and can occur in patients of all ages $[151,167]$. Some authors hypothesize that AD-induced emotional blunting occurs as a result of a downregulation of dopamine neurotransmission in neural circuits that regulate reward processing, secondary to an activation of $5-\mathrm{HT} 2{ }_{\mathrm{C}}$ receptors in the nucleus accumbens [168]. These changes in emotional processing are not limited to SSRIs, and have also been reported for patients taking mirtazapine, agomelatine and reboxetine [167]. In addition, cases of apathy, lack of motivation and frontal lobe syndrome have been described in patients taking SSRIs in adults, adolescents and children [24].

Treatment with ADs has been associated with mania or other forms of excessive behavioral activation [169, 170]. These responses may unveil unrecognized bipolar illness or may be drug induced since they may also occur in allegedly unipolar patients. A meta-analysis indicates that the treatment of juvenile patients for both anxiety and depressive disorders may lead to excessive arousal activation and even hypomania, which calls for a proper clinical monitoring for the emergence of bipolar disorder [171]. Furthermore, an activation syndrome in which patients taking antidepressants may experience anxiety, agitation, panic attacks, insomnia, irritability, hostility, aggressiveness and impulsivity in the first 3 months of treatment may ensue [172].

The use of ADs may be associated not only with the return of depressive symptoms during maintenance treatment, but also with the appearance of new symptoms and exacerbation of the baseline clinical picture (paradoxical effects). Improvement may result from AD discontinuation [173]. The occurrence of paradoxical effects was reported in RCTs with fluoxetine [174] and sertraline [175].

\section{Suicidality}

The emergence of suicidality and self-injurious behavior upon treatment with ADs represents one of the most debated and controversial risks associated with antidepressant use [176-179]. Since 2014, the US Food and Drug Administration (FDA) issued a black box warning regarding the risk of suicidality related to the use of antidepressants in children and adolescents [179]. The incidence of suicide and attempted suicide has been a frequently underreported adverse outcome across antidepressant RCTs [180]. The first association between the use of SSRIs and suicidality was reported in 1990 [181]. The risk-to-benefit assessment of the use of antidepressants in children and adolescents considering the potential risk of suicidality is complex [182]. The potential therapeutic benefits have modest to moderate effect sizes, while a recent meta-analysis found a significant risk of suicide $(\mathrm{OR}=2.79 ; 95 \% \mathrm{CI}=1.62-4.81)$ [183], although the underreporting of data limits the establishment of causal inferences. The risk of suicidality in pediatric populations treated with antidepressants could be a source of greater concern when higher doses are used [184]. Therefore, clinical monitoring regarding the emergence of suicidality throughout treatment is a necessary step.

Two recent meta-analyses have not identified a clear increased risk of treatment-emergent suicidality in adult individuals treated with antidepressants in RCTs [180, 183]. Notwithstanding that the use of antidepressants is efficacious for the treatment of MDD in adults, there is no clear evidence for either specific protective effects or increased risk related to suicidality. An expert statement issued by the European Psychiatric Association (EPA) mentions that antidepressants decrease suicidality [185], but there is no consistent evidence to support this statement.

\section{Safety in Overdose}

Patients with MDD are at increased risk of suicide and overdosing of prescribed medications is a common method used to attempted suicide [186]. Therefore, the safety 
of distinct antidepressants in overdose is a matter of concern [23]. One study reviewed records in the UK and found that among antidepressants the case fatality rate (ratios of deaths to nonfatal overdose) was highest for TCAs (1.6) followed by venlafaxine (0.29) and mirtazapine (0.22), and was lowest for SSRIs (0.06). Among the SSRIs, citalopram was found to be associated with the highest case fatality rates in overdose [187]. Another study investigated poison control data in the USA from 2000 to 2004. Likewise, TCAs were associated with the highest mortality rates due to overdose. Among the newer antidepressants, bupropion and venlafaxine were associated with the highest case fatality rates. In addition, among SSRIs, citalopram and fluvoxamine appeared to be related to higher mortality rates in overdose, whereas fluoxetine and sertraline were the safest [188]. Due to the limited available evidence, it seems clear that TCAs are associated with higher case fatality rates compared to SSRIs, while the relative ranking of different SSRIs deserves further investigation.

\section{Discontinuation Syndromes}

An often underappreciated clinical problem associated with the use of almost all SSRIs and SNRIs is the emergence of withdrawal symptoms of varying degrees of severity upon treatment discontinuation and/or interruption [189, 190]. These symptoms include flu-like symptoms, tremors, tachycardia, shock-like sensations, paresthesia, myalgia, tinnitus, neuralgia, ataxia, vertigo, sexual dysfunction, sleep disturbances, vivid dreams, nausea vomiting, diarrhea, worsening anxiety and mood instability [190]. A recent review suggested that dependence and withdrawal symptoms associated with newer antidepressants were comparable, if not worse, to those experienced with benzodiazepines [190]. These reactions have been defined as 'discontinuation syndromes', with the aim of avoiding any hint to a potential for dependence that may affect marketing $[190,191]$. Due to the severity and unpredictability of these manifestations, it has been recently suggested that the term 'discontinuation syndrome' should be replaced by 'withdrawal syndrome' [190]. Symptoms typically appear within 3-4 days of stopping an antidepressant or initiating a medication taper. They may be mild and resolve spontaneously within 1-3 weeks; in other cases, they may persist for months or even years, leading to what has been defined as 'persistent postwithdrawal disorder' [192]. In addition, following the abrupt interruption of antide- pressants, a manic or hypomanic episode may occur [193]. These symptoms can start within a few days to weeks (partly depending on the half-life of the agent used). Withdrawal symptoms are most prominent in agents with shorter half-lives and high potency, such as venlafaxine and paroxetine [190, 194]. Interestingly, most studies show that although tapering the drug over a period of weeks to months may confer some advantages, it does not eliminate the probability of developing withdrawal symptoms [190].

Alternative strategies for the management of antidepressant-related withdrawal syndrome are scarce, and the quality of the evidence is limited [189]. A combination of cognitive behavior therapy and well-being therapy has been reported to be successful in a case series for managing persistent postwithdrawal disorders [195].

\section{Ophthalmic Effects}

A subset of patients taking SSRIs reports nonspecific visual disturbances [196], which may be a cause of AD withdrawal [197]. A subsequent review indicates that the use of different SSRIs may increase intraocular pressure and lead to the emergence of angle-closure glaucoma [198], which case reports have also indicated may be caused by venlafaxine [199, 200]. In addition, a nested case-control study found that that the risk of angle-closure glaucoma was doubled among patients younger than 50 years taking bupropion [201]. Two analyses were performed using data derived from the Taiwan National Health Insurance database [202, 203]. While the use of SSRIs was associated with a substantial independent risk of acute angle-closure glaucoma $(\mathrm{OR}=5.80 ; 95 \% \mathrm{CI}=$ 1.89-17.9) [203], there was no apparent risk of either primary angle-closure glaucoma or primary open-angle glaucoma in patients with depression on long-term SSRI use [202]. Available evidence indicates that baseline and follow-up ophthalmic consultations may be warranted in patients taking SSRIs with a higher risk for glaucoma (e.g. the elderly and those with a familial high risk of glaucomatous diseases) [204].

A nested case-control study found a higher likelihood of cataracts after exposure to newer generation antidepressants, including fluvoxamine $(\mathrm{RR}=1.39,95 \% \mathrm{CI}=$ $1.07-180)$, followed by venlafaxine $(\mathrm{RR}=1.33,95 \% \mathrm{CI}=$ $1.14-1.55)$ and paroxetine $(1.23,95 \% \mathrm{CI}=1.05-1.45)$ [205]. These findings were replicated in another casecontrol registry study [206]. 


\section{Hyperprolactinemia}

Prolactin release is primarily regulated by tuberoinfundibular dopamine pathways, but it is also modulated indirectly by serotonin via the activation of $5-\mathrm{HT}_{1 \mathrm{C}}$ and $5-\mathrm{HT}_{2}$ receptors [207]. Long-standing increases in peripheral prolactin levels are occasionally observed in patients using ADs, including SSRIs [208]; hyperprolactinemia may have deleterious health consequences (e.g. a decrease in BMD and hypogonadism) [209]. The routine monitoring of prolactin levels is not recommended, but the measurement of plasma prolactin is necessary when symptoms suggest the possibility of hyperprolactinemia. Where hyperprolactinemia is confirmed, a switch to mirtazapine may be a good therapeutic choice, although a switch to another SSRI may also stop this abnormality [210]. Finally, there are case reports of normoprolactinemic galactorrhea related to the use of ADs $[211,212]$.

\section{Risks during Pregnancy and Breast Feeding}

Pregnant women have an increased risk of developing depressive illness and about $10-15 \%$ of them experience depression during pregnancy. The risk of depression appears to be highest in the second and third trimester and almost half of these women continue to have symptoms after the end of pregnancy [213]. It is important to treat MDD during pregnancy as it has been associated with an increased risk of complications during pregnancy, including increased risk of preeclampsia, preterm birth, abnormal bleeding, miscarriages and even fetal death [214]. Even though an extensive discussion about the potential benefits and harms associated with the use of different ADs during pregnancy and breast feeding is beyond the scope of our review, we will briefly discuss key clinical issues. We refer the reader to a recent review on the topic for a wider debate [215].

Studies examining the effect of exposure to SSRIs during pregnancy and its association with birth defects have been marred by several confounders, such as the detrimental effects of MDD itself, maternal age, smoking and use of other medications (e.g. anticonvulsants) [214]. After controlling for these factors, SSRIs have not been unequivocally associated with an increased risk of major birth defects [216]. Most of the data describing the presence of birth defects associated with SSRI use have been based on observational studies and drug registries. Therefore, the clinical significance of these data is questionable.
SSRIs have been associated with a modest increase in risk of congenital cardiac malformations, with a relative risk of about 1.4, as well as with an increased risk of postpartum hemorrhage $[217,218]$. In addition, paroxetine has been associated with an increased risk of congenital cardiac defects and should not be used during pregnancy $[217,219]$. A recent meta-analysis indicated that exposure to SSRIs in late pregnancy may confer an increased risk of persistent pulmonary hypertension [220]. However, the absolute risk was small, and thus the clinical significance of this finding seems rather limited. Fluoxetine has the largest amount of data; however, this drug is slowly eliminated by the newborn (see below).

Exposure to SNRIs (e.g. duloxetine and venlafaxine) during pregnancy does not seem to be consistently associated with an increased risk of birth defects, but use of these medications has been associated with an increased risk of postpartum hemorrhage, and venlafaxine in particular has been associated with an increased risk of hypertension during pregnancy [221-223]. However, it is important to remember that the data investigating the safety of exposure to SNRIs during pregnancy are not as extensive as those for SSRIs. Similarly, most data suggest that the risk associated with the use of bupropion, mirtazapine and trazodone during pregnancy is low, while some studies have shown equivocal results regarding the potential risk cardiac malformation related to bupropion use [224-227].

The placental transfer of different antidepressant medications varies [228]. The use of SSRIs and SNRIs during late pregnancy has been associated with withdrawal reactions characterized by irritability, excessive crying, tremor and even seizures [229]. These reactions at least to a certain extent may be conceptualized as discontinuation or withdrawal syndromes [230]. In fact, paroxetine and venlafaxine, two antidepressants with relatively short half-lives, have been especially associated with withdrawal reactions [223].

The benefits of treating depression during pregnancy and lactation should be balanced against the risks associated with the treatment itself. Depending on the severity and degree of recurrence of the underlying illness, if the patient is already stabilized on a specific antidepressant, a recent expert panel advises that the patient should be maintained on the same medication, except in the case of paroxetine [215]. Whenever the patient is drug-naïve, sertraline and citalopram appear to be the best therapeutic option [215]. The use of TCAs (with the exception of doxepin) is also a relatively safe option during breast feeding [231]. 


\section{Risk of Malignancies}

Evidence which links antidepressants with increased risk of different types of cancer originates from animal studies and the results from clinical studies appear to be mixed. Most observational studies have been limited by confounders (e.g. age, the use of other medication and smoking). Preclinical studies have found that antidepressants can increase the growth of fibrosarcomas and melanomas, and may also promote mammary carcinogenesis [232]. However, other animal studies have reported the opposite trend (i.e. antidepressant use has been shown to have protective effects in tumor models) [233235].

A review has found that the associations between the use of SSRIs and TCAs with either breast or ovarian cancer have been mixed across studies [236]. Similarly, a previous meta-analysis of eighteen studies did not support an association between the use of TCAs and SSRIs with breast cancer [237]. However, it should be mentioned that the concomitant use of SSRIs which inhibit the CYP450 2D6 isoenzyme (e.g. paroxetine) and tamoxifen may increase breast cancer-related mortality [238]. In summary, limitations in the overall quality of available evidence do not allow the establishment of causal inferences linking exposure to antidepressants and carcinogenesis [239]. Although clinicians might need to be vigilant when treating female patients with a high risk of breast/ovarian cancer with ADs [240], there is no absolute contraindication to the use of $\mathrm{ADs}$ in women with breast cancer [241].

\section{Conclusions}

It is a common belief that newer generation antidepressants (and particularly SSRIs) have fewer side effects than TCAs. This assumption only pertains to the safety of ADs in overdose. On the contrary, the long-term use of SSRIs and SNRIs is likely to yield important side effects, which are summarized in table 1 . The likelihood of treatment-emergent adverse effects are related to the duration of $\mathrm{AD}$ treatment, which has been found to be the case regarding weight gain [53], diabetes [64, 242] and osteoporosis [243].

Some AD-related side effects may persist long after treatment discontinuation. These latter phenomena led to the introduction of the concept of iatrogenic comorbidity in adults [244, 245]. ADs, particularly following long-term use, may increase the risk of experiencing ad- ditional psychopathological (e.g. treatment emergent affective switches and paradoxical symptoms), or medical (e.g. obesity and bleeding) problems that do not necessarily subside after discontinuation of the drug, and that may modify responsiveness to subsequent treatments [173]. An issue of concern is that other newer generation ADs have not been used as extensively as SSRIs, SNRIs and TCAs. As Karch and Lasagna [246] note, the history of toxicology reminds us vividly of the lag that often occurs between the first approval of a drug for use in humans and the recognition of certain adverse events from that drug.

There is a tendency to protract treatment for long periods of time, with a widely held belief that it may be protective against recurrences. A meta-analysis indicates that the use of ADs may reduce the risk of recurrences in the maintenance phase [247]. However, patients with multiple major depressive episodes may experience significantly less benefit from long-term AD treatment compared to patients with single episodes [247]. This finding indicates that in patients with chronic recurring MDD, recurrences are difficult to prevent with $\mathrm{AD}$ use only. Furthermore, an extensive body of evidence, reviewed in detail elsewhere [173], suggests that the likelihood of relapse increases as a function of the duration of AD treatment. Hence, it has been suggested that the use of ADs should be limited to those patients with the more severe and chronic forms of MDD, for the shortest possible period of time.

The findings of this review suggest that long-term treatment with new generation ADs should be avoided if alternative treatments are available. The sequential use of pharmacotherapy in the acute phase of depression and of psychotherapy in its residual stage may allow the tapering and discontinuation of ADs, with significant clinical advantages [248].

It is thus important to place clinical decisions concerning the use of ADs in the framework of risk (the likelihood of poor outcomes from an index disorder if therapy is withheld), responsiveness to the treatment option, vulnerability to the adverse effects of treatment and availability of nonpharmacological options [173, 249].

\section{Acknowledgements}

A.F.C. and A.R.B. are supported by a research fellowship award from $\mathrm{CNPq}$ (Brazil). We are grateful to Nicoletta Sonino, MD, for her helpful comments and advice. 


\section{Disclosure Statement}

No external company or institution has funded this work. A.F.C., M.S.S., A.R.B. and G.A.F. report no conflicts of interest. E.V. has received grants, CME-related honoraria or consulting fees from Alexza, Almirall, AstraZeneca, Bristol-Myers Squibb, Cephalon, Eli Lilly and Co., Ferrer, Forest Research Institute, Gedeon
Richter, GlaxoSmithKline, Janssen, Janssen-Cilag, Jazz, Johnson and Johnson, Lundbeck, Merck, Novartis, Organon, Otsuka, Pfizer, Pierre-Fabre, Qualigen, Roche, Sanofi-Aventis, ScheringPlough, Servier, Shire, Solvay, Takeda, Teva, CIBERSAM, the Seventh European Framework Programme (ENBREC), the Stanley Medical Research Institute, United Biosource Corporation, and Wyeth.

\section{References}

1 Kessler RC: The costs of depression. Psychiatr Clin North Am 2012;35:1-14.

2 Mathers CD, Loncar D: Projections of global mortality and burden of disease from 2002 to 2030. PLoS Med 2006;3:e442.

3 Pratt LA, Brody DJ, Gu Q: Antidepressant use in persons aged 12 and over: United States, 2005-2008. NCHS Data Brief 2011;76:1-8.

4 Castro-Rodríguez JI, Olariu E, GarnierLacueva C, Martín-López LM, Pérez-Solà V, Alonso J, Forero CG; INSAyD Investigators: Diagnostic accuracy and adequacy of treatment of depressive and anxiety disorders: a comparison of primary care and specialized care patients. J Affect Disord 2015;172:462471.

5 Duhoux A, Fournier L, Gauvin L, Roberge P: What is the association between quality of treatment for depression and patient outcomes? A cohort study of adults consulting in primary care. J Affect Disord 2013;151:265274.

6 Yau WY, Chan MC, Wing YK, Lam HB, Lin W, Lam SP, Lee CP: Noncontinuous use of antidepressant in adults with major depressive disorders - a retrospective cohort study. Brain Behav 2014;4:390-397.

7 Hung CI: Factors predicting adherence to antidepressant treatment. Curr Opin Psychiatry 2014; 27:344-349.

8 Fortney JC, Pyne JM, Edlund MJ, Stecker T, Mittal D, Robinson DE, Henderson KL: Reasons for antidepressant nonadherence among veterans treated in primary care clinics. J Clin Psychiatry 2011;72:827-834.

9 Bull SA, Hunkeler EM, Lee JY, Rowland CR, Williamson TE, Schwab JR, Hurt SW: Discontinuing or switching selective serotoninreuptake inhibitors. Ann Pharmacother 2002; 36:578-584.

10 Anderson IM: Selective serotonin reuptake inhibitors versus tricyclic antidepressants: a meta-analysis of efficacy and tolerability. J Affect Disord 2000;58:19-36.

11 Machado-Vieira R, Henter ID, Zarate CA: New targets for rapid antidepressant action. Prog Neurobiol 2015, Epub ahead of print.

12 Rosenblat JD, McIntyre RS, Alves GS, Fountoulakis $\mathrm{KN}$, Carvalho AF: Beyond monoamines-novel targets for treatment-resistant depression: a comprehensive review. Curr Neuropharmacol 2015;13:636-655.
13 Hatcher S, Arroll B: Newer antidepressants for the treatment of depression in adults. BMJ 2012;344:d8300-d8300.

14 Elmaadawi A, Singh N, Reddy J: Prescriber's guide to using 3 new antidepressants. Curr Psychiatry 2016;14:32-36.

15 Cipriani A, Furukawa TA, Salanti G, Geddes JR, Higgins JP, Churchill R, Watanabe N, Nakagawa A, Omori IM, McGuire H, Tansella M, Barbui C: Comparative efficacy and acceptability of 12 new-generation antidepressants: a multiple-treatments meta-analysis. Lancet 2009;373:746-758.

16 Khoo AL, Zhou HJ, Teng M, Lin L, Zhao YJ, Soh LB, Mok YM, Lim BP, Gwee KP: Network meta-analysis and cost-effectiveness analysis of new generation antidepressants. CNS Drugs 2015;29:695-712.

17 Baghai TC, Blier P, Baldwin DS, Bauer M, Goodwin GM, Fountoulakis KN, Kasper S, Leonard BE, Malt UF, Stein D, Versiani M, Möller HJ; Section of Pharmacopsychiatry, World Psychiatric Association: General and comparative efficacy and effectiveness of antidepressants in the acute treatment of depressive disorders: a report by the WPA section of pharmacopsychiatry. Eur Arch Psychiatry Clin Neurosci 2011;261(suppl): 207-245.

18 Gartlehner G, Gaynes BN, Hansen RA, Thieda P, DeVeaugh-Geiss A, Krebs EE, Moore CG, Morgan L, Lohr KN: Comparative benefits and harms of second-generation antidepressants: background paper for the American College of Physicians. Ann Intern Med 2008;149:734-750.

19 Fountoulakis KN, McIntyre RS, Carvalho AF: From randomized controlled trials of antidepressant drugs to the meta-analytic synthesis of evidence: methodological aspects lead to discrepant findings. Curr Neuropharmacol 2015; 13:605-615.

20 von Wolff A, Hölzel LP, Westphal A, Härter $M$, Kriston L: Selective serotonin reuptake inhibitors and tricyclic antidepressants in the acute treatment of chronic depression and dysthymia: a systematic review and metaanalysis. J Affect Disord 2013;144:7-15.
21 Barbui C, Hotopf M, Freemantle N, Boynton J, Churchill R, Eccles M, Geddes J, Hardy R, Lewis G, Mason J: Selective serotonin reuptake inhibitors versus tricyclic and heterocyclic antidepressants: comparison of drug adherence. Cochrane Database Syst Rev 2000; 4:CD002791.

22 Thase ME, Denko T: Pharmacotherapy of mood disorders. Annu Rev Clin Psychol 2008; 4:53-91.

23 Peretti S, Judge R, Hindmarch I: Safety and tolerability considerations: tricyclic antidepressants vs. selective serotonin reuptake inhibitors. Acta Psychiatr Scand Suppl 2000; 403:17-25.

24 Moret C, Isaac M, Briley M: Problems associated with long-term treatment with selective serotonin reuptake inhibitors. J Psychopharmacol 2009;23:967-974.

25 Whiskey E, Taylor D: A review of the adverse effects and safety of noradrenergic antidepressants. J Psychopharmacol 2013;27:732739

26 Gershon MD: 5-hydroxytryptamine (serotonin) in the gastrointestinal tract. Curr Opin Endocrinol Diabetes Obes 2013;20:14-21.

27 Janssen P, Vos R, Tack J: The influence of citalopram on interdigestive gastrointestinal motility in man. Aliment Pharmacol Ther 2010; 32:289-295.

28 Browning KN: Role of central vagal 5-HT3 receptors in gastrointestinal physiology and pathophysiology. Front Neurosci 2015;9:413.

29 Goldstein BJ, Goodnick PJ: Selective serotonin reuptake inhibitors in the treatment of affective disorders - III: tolerability, safety and pharmacoeconomics. J Psychopharmacol 1998;12:S55-S87.

30 Uher R, Farmer A, Henigsberg N, Rietschel M, Mors O, Maier W, Kozel D, Hauser J, Souery D, Placentino A, Strohmaier J, Perroud N, Zobel A, Rajewska-Rager A, Dernovsek MZ, Larsen ER, Kalember P, Giovannini C, Barreto M, McGuffin P, Aitchison KJ: Adverse reactions to antidepressants. $\mathrm{Br} \mathrm{J}$ Psychiatry 2009;195:202-210.

31 Wang YP, Chen YT, Tsai CF, Li SY, Luo JC, Wang SJ, Tang CH, Liu CJ, Lin HC, Lee FY, Chang FY, Lu CL: Short-term use of serotonin reuptake inhibitors and risk of upper gastrointestinal bleeding. Am J Psychiatry 2014;171: 54-61. 
32 Mackay FJ, Dunn NR, Wilton LV, Pearce GL, Freemantle SN, Mann RD: A comparison of fluvoxamine, fluoxetine, sertraline and paroxetine examined by observational cohort studies. Pharmacoepidemiol Drug Saf 1997;6: 235-246.

33 Mackay FR, Dunn NR, Martin RM, Pearce GL, Freemantle SN, Mann RD: Newer antidepressants: a comparison of tolerability in general practice. Br J Gen Pract 1999;49:892-896.

34 Spigset O: Adverse reactions of selective serotonin reuptake inhibitors: reports from a spontaneous reporting system. Drug Saf 1999; 20:277-287.

35 Gartlehner G, Hansen RA, Reichenpfader U, Kaminski A, Kien C, Strobelberger M, van Noord M, Thieda P, Thaler K, Gaynes B: Drug Class Review: Second-Generation Antidepressants: Final Update 5 Report. Drug Class Reviews. Portland, Oregon Health and Science University, 2011.

36 DeVane CL: Immediate-release versus controlled-release formulations: pharmacokinetics of newer antidepressants in relation to nausea. J Clin Psychiatry 2003;64(suppl 1):14-19.

37 Nussbaumer B, Morgan LC, Reichenpfader U, Greenblatt A, Hansen RA, van Noord M, Lux L, Gaynes BN, Gartlehner G: Comparative efficacy and risk of harms of immediateversus extended-release second-generation antidepressants: a systematic review with network meta-analysis. CNS Drugs 2014;28: 699-712.

38 Asnis GM, Henderson MA: Levomilnacipran for the treatment of major depressive disorder: a review. Neuropsychiatr Dis Treat 2015; 11:125-135.

39 Meeker AS, Herink MC, Haxby DG, Hartung DM: The safety and efficacy of vortioxetine for acute treatment of major depressive disorder: a systematic review and meta-analysis. Syst Rev 2015;4:21.

40 Yu SY, Zhang XF, Wu L, Wan DJ, Liu RZ, Dong Z, Chen M: Evaluation of the efficacy and safety of vilazodone for treating major depressive disorder. Neuropsychiatr Dis Treat 2015;11:1957-1965.

41 Voican CS, Corruble E, Naveau S, Perlemuter G: Antidepressant-induced liver injury: a review for clinicians. Am J Psychiatry 2014;171: 404-415.

42 Chen M, Borlak J, Tong W: High lipophilicity and high daily dose of oral medications are associated with significant risk for drug-induced liver injury. Hepatology 2013;58:388396.

43 Dara L, Liu Z-X, Kaplowitz N: Mechanisms of adaptation and progression in idiosyncratic drug induced liver injury, clinical implications. Liver Int 2016;36:158-165.

44 Hussaini SH, Farrington EA: Idiosyncratic drug-induced liver injury: an update on the 2007 overview. Expert Opin Drug Saf 2014; 13:67-81.
45 Choi S: Nefazodone (Serzone) withdrawn because of hepatotoxicity. CMAJ 2003;169: 1187.

46 Freiesleben SD, Furczyk K: A systematic review of agomelatine-induced liver injury. J Mol Psychiatry 2015;3:4.

47 Mitkov MV, Trowbridge RM, Lockshin BN, Caplan JP: Dermatologic side effects of psychotropic medications. Psychosomatics 2014; 55:1-20.

48 Bliss SA, Warnock JK: Psychiatric medications: adverse cutaneous drug reactions. Clin Dermatol 2013;31:101-109.

49 Hedenmalm K, Sundstrom A, Spigset O: Alopecia associated with treatment with selective serotonin reuptake inhibitors (SSRIs). Pharmacoepidemiol Drug Saf 2006;15:719-725.

50 Fava M: Weight gain and antidepressants. J Clin Psychiatry 2000;61(suppl 1):37-41.

51 Serretti A, Mandelli L: Antidepressants and body weight: a comprehensive review and meta-analysis. J Clin Psychiatry 2010;71: 1259-1272.

52 Zimmermann U, Kraus T, Himmerich $\mathrm{H}$, Schuld A, Pollmächer T: Epidemiology, implications and mechanisms underlying druginduced weight gain in psychiatric patients. J Psychiatr Res 2003;37:193-220.

53 Lee SH, Paz-Filho G, Mastronardi C, Licinio J, Wong ML: Is increased antidepressant exposure a contributory factor to the obesity pandemic? Transl Psychiatry 2016;6:e759.

54 Patten SB, Williams JV, Lavorato DH, Brown L, McLaren L, Eliasziw M: Major depression, antidepressant medication and the risk of obesity. Psychother Psychosom 2009;78:182186.

55 Fava GA, Offidani E: The mechanisms of tolerance in antidepressant action. Prog Neuropsychopharmacol Biol Psychiatry 2011;35: 1593-1602.

56 Sussman N, Ginsberg DL: Weight effects of nefazodone, bupropion, mirtazapine, and venlafaxine: a review of available evidence. Primary Psychiatry 2000;7:33-48.

57 Gadde KM, Parker CB, Maner LG, Wagner HR, Logue EJ, Drezner MK, Krishnan KR: Bupropion for weight loss: An investigation of efficacy and tolerability in overweight and obese women. Obes Res 2001;9:544-551.

58 Silverstone $\mathrm{PH}$, Ravindran A: Once-daily venlafaxine extended release (XR) compared with fluoxetine in outpatients with depression and anxiety. Venlafaxine XR 360 study group. J Clin Psychiatry 1999;60:22-28.

59 Citrome L: Vortioxetine for major depressive disorder: an indirect comparison with duloxetine, escitalopram, levomilnacipran, sertraline, venlafaxine, and vilazodone, using number needed to treat, number needed to harm, and likelihood to be helped or harmed. J Affect Disord 2016;196:225-233.
60 Citrome L: Vilazodone for major depressive disorder: a systematic review of the efficacy and safety profile for this newly approved antidepressant - what is the number needed to treat, number needed to harm and likelihood to be helped or harmed? Int J Clin Pract 2012; 66:356-368.

61 McIntyre RS, Soczynska JK, Konarski JZ, Kennedy SH: The effect of antidepressants on lipid homeostasis: a cardiac safety concern? Expert Opin Drug Saf 2006;5:523-537.

62 Correll CU, Detraux J, De Lepeleire J, De Hert M: Effects of antipsychotics, antidepressants and mood stabilizers on risk for physical diseases in people with schizophrenia, depression and bipolar disorder. World Psychiatry 2015;14:119-136.

63 Deuschle M: Effects of antidepressants on glucose metabolism and diabetes mellitus type 2 in adults. Curr Opin Psychiatry 2013; 26:60-65.

64 Andersohn F, Schade R, Suissa S, Garbe E: Long-term use of antidepressants for depressive disorders and the risk of diabetes mellitus. Am J Psychiatry 2009;166:591-598.

65 Kivimaki M, Hamer M, Batty GD, Geddes JR, Tabak AG, Pentti J, Virtanen M, Vahtera J: Antidepressant medication use, weight gain, and risk of type 2 diabetes: a population-based study. Diabetes Care 2010;33:2611-2616.

66 Da Silva MA, Dugravot A, Balkau B, Roussel R, Fumeron F, Elbaz A, Canonico M, SinghManoux A, Nabi H: Antidepressant medication use and trajectories of fasting plasma glucose, glycated haemoglobin, $\beta$-cell function and insulin sensitivity: a 9-year longitudinal study of the D.E.S.I.R. Cohort. Int J Epidemiol 2015;44:1927-1940.

67 Bhattacharya R, Ajmera M, Bhattacharjee S, Sambamoorthi U: Use of antidepressants and statins and short-term risk of new-onset diabetes among high risk adults. Diabetes Res Clin Pract 2014;105:251-260.

68 Bhattacharjee S, Bhattacharya R, Kelley GA, Sambamoorthi U: Antidepressant use and new-onset diabetes: a systematic review and meta-analysis. Diabetes Metab Res Rev 2013; 29:273-284.

69 Kivimaki M, Batty GD, Jokela M, Ebmeier KP, Vahtera J, Virtanen M, Brunner EJ, Tabak AG, Witte DR, Kumari M, Singh-Manoux A, Hamer M: Antidepressant medication use and risk of hyperglycemia and diabetes mellitus: a noncausal association? Biol Psychiatry 2011;70:978-984.

70 Pacher P, Ungvari Z, Nanasi PP, Furst S, Kecskemeti V: Speculations on difference between tricyclic and selective serotonin reuptake inhibitor antidepressants on their cardiac effects: is there any? Curr Med Chem 1999; 6:469-480.

71 Sarlon J, Habich O, Schneider B: Elevated rest heart rate in psychiatric patients and different effects of psychotropic medication. Pharmacopsychiatry 2016;49:18-22. 
72 Thase ME, Larsen KG, Reines E, Kennedy SH: The cardiovascular safety profile of escitalopram. Eur Neuropsychopharmacol 2013;23: 1391-1400.

73 Kemp AH, Brunoni AR, Santos IS, Nunes MA, Dantas EM, Carvalho de Figueiredo R, Pereira AC, Ribeiro ALP, Mill JG, Andreão RV, Thayer JF, Benseñor IM, Lotufo PA: Effects of depression, anxiety, comorbidity, and antidepressants on resting-state heart rate and its variability: an ELSA-Brasil cohort baseline study. Am J Psychiatry 2014;171: 1328-1334.

74 Goldstein DJ: Duloxetine in the treatment of major depressive disorder. Neuropsychiatr Dis Treat 2007;3:193-209.

75 O’Regan C, Kenny RA, Cronin H, Finucane C, Kearney PM: Antidepressants strongly influence the relationship between depression and heart rate variability: findings from the Irish longitudinal study on ageing (TILDA). Psychol Med 2015;45:623-636.

76 Taylor CB: Depression, heart rate related variables and cardiovascular disease. Int J Psychophysiol 2010;78:80-88.

77 Schatzberg AF, Blier P, Culpepper L, Jain R, Papakostas GI, Thase ME: An overview of vortioxetine. J Clin Psychiatry 2014;75:14111418.

78 Funk KA, Bostwick JR: A comparison of the risk of QT prolongation among SSRIs. Ann Pharmacother 2013;47:1330-1341.

79 Beach SR, Celano CM, Noseworthy PA, Januzzi JL, Huffman JC: QTc prolongation, torsades de pointes, and psychotropic medications. Psychosomatics 2013;54:1-13.

80 Beach SR, Kostis WJ, Celano CM, Januzzi JL, Ruskin JN, Noseworthy PA, Huffman JC: Meta-analysis of selective serotonin reuptake inhibitor-associated QTc prolongation. J Clin Psychiatry 2014;75:e441-e449.

81 Feighner JP: Cardiovascular safety in depressed patients: focus on venlafaxine. J Clin Psychiatry 1995;56:574-579.

82 Thase ME, Tran PV, Wiltse C, Pangallo BA, Mallinckrodt C, Detke MJ: Cardiovascular profile of duloxetine, a dual reuptake inhibitor of serotonin and norepinephrine. J Clin Psychopharmacol 2005;25:132-140.

83 Pollock BG: Adverse reactions of antidepressants in elderly patients. J Clin Psychiatry 1999;60(suppl 2):4-8.

84 Rodriguez de la Torre B, Dreher J, Malevany I, Bagli M, Kolbinger M, Omran H, Lüderitz B, Rao ML: Serum levels and cardiovascular effects of tricyclic antidepressants and selective serotonin reuptake inhibitors in depressed patients. Ther Drug Monit 2001;23: 435-440.

85 Darowski A, Chambers SA, Chambers DJ: Antidepressants and falls in the elderly. Drugs Aging 2009;26:381-394.

86 Joo JH, Lenze EJ, Mulsant BH, Begley AE, Weber EM, Stack JA, Mazumdar S, Reynolds CF, Pollock BG: Risk factors for falls during treatment of late-life depression. J Clin Psychiatry 2002;63:936-941.
87 Cherin P, Colvez A, Deville de Periere G, Sereni D: Risk of syncope in the elderly and consumption of drugs: a case-control study. J Clin Epidemiol 1997;50:313-320.

88 Johnson EM, Whyte E, Mulsant BH, Pollock BG, Weber E, Begley AE, Reynolds CF: Cardiovascular changes associated with venlafaxine in the treatment of late-life depression. Am J Geriatr Psychiatry 2006;14:796802.

89 Khawaja IS, Feinstein RE: Cardiovascular effects of selective serotonin reuptake inhibitors and other novel antidepressants. Heart Dis 2003;5:153-160.

90 Verhamme KMC, Sturkenboom MC, Stricker BHC, Bosch R: Drug-induced urinary retention: Incidence, management and prevention. Drug Saf 2008;31:373-388.

91 Thor KB: Serotonin and norepinephrine involvement in efferent pathways to the urethral rhabdosphincter: implications for treating stress urinary incontinence. Urology 2003;62:3-9.

92 Votolato NA, Stern S, Caputo RM: Serotonergic antidepressants and urinary incontinence. Int Urogynecol J Pelvic Floor Dysfunct 2000; $11: 386-388$.

93 Tsakiris P, Oelke M, Michel MC: Drug-induced urinary incontinence. Drugs Aging 2008; $25: 541-549$

94 Williams K, Reynolds MF: Sexual dysfunction in major depression. CNS Spectr 2006; 11:19-23.

95 Clayton AH, Croft HA, Handiwala L: Antidepressants and sexual dysfunction: mechanisms and clinical implications. Postgrad Med 2014;126:91-99.

96 Serretti A, Chiesa A: Treatment-emergent sexual dysfunction related to antidepressants: a meta-analysis. J Clin Psychopharmacol 2009;29:259-266.

97 Rizvi SJ, Yeung NW, Kennedy SH: Instruments to measure sexual dysfunction in community and psychiatric populations. J Psychosom Res 2011;70:99-109.

98 Kikuchi T, Uchida H, Suzuki T, Watanabe K, Kashima H: Patients' attitudes toward side effects of antidepressants: an internet survey. Eur Arch Psychiatry Clin Neurosci 2011;261:103-109.

99 Balon R, Segraves RT: Survey of treatment practices for sexual dysfunction(s) associated with anti-depressants. J Sex Marital Ther 2008;34:353-365.

100 Bella AJ, Shamloul R: Psychotropics and sexual dysfunction. Cent Eur J Urol 2013;66: 466-471.

101 Reichenpfader U, Gartlehner G, Morgan LC, Greenblatt A, Nussbaumer B, Hansen RA, van Noord M, Lux L, Gaynes BN: Sexual dysfunction associated with second-generation antidepressants in patients with major depressive disorder: results from a systematic review with network meta-analysis. Drug Saf 2014;37:19-31.
102 Schweitzer I, Maguire K, Ng C: Sexual sideeffects of contemporary antidepressants: review. Aust NZ J Psychiatry 2009;43:795808.

103 Gartlehner GH, Hansen RA, Reichenpfader UK, Kaminski A, Kien C, Strobelberger MN, van Noord M, Thieda P, Thaler K, Gaynes B: Drug Class Review: Second-Generation Antidepressants: Final Update 5 Report. Drug Class Reviews. Portland, Oregon Health and Science University, 2011.

104 Angst J: Sexual problems in healthy and depressed persons. Int Clin Psychopharmacol 1998;13(suppl 6):S1-S4.

105 Montejo AL, Montejo L, Navarro-Cremades F: Sexual side-effects of antidepressant and antipsychotic drugs. Curr Opin Psychiatry 2015;28:418-423.

106 Clayton AH, El Haddad S, Iluonakhamhe J-P, Ponce Martinez C, Schuck AE: Sexual dysfunction associated with major depressive disorder and antidepressant treatment. Expert Opin Drug Saf 2014;13:13611374.

107 Montgomery SA, Baldwin DS, Riley A: Antidepressant medications: a review of the evidence for drug-induced sexual dysfunction. J Affect Disord 2002;69:119-140.

108 Segraves RT, Balon R: Antidepressant-induced sexual dysfunction in men. Pharmacol Biochem Behav 2014;121:132-137.

109 Pereira VM, Arias-Carrión O, Machado S, Nardi AE, Silva AC: Bupropion in the depression-related sexual dysfunction: a systematic review. CNS Neurol Disord Drug Targets 2014;13:1079-1088.

110 Csoka AB, Shipko S: Persistent sexual side effects after SSRI discontinuation. Psychother Psychosom 2006;75:187-188.

111 de Picker L, van Den Eede F, Dumont G, Moorkens G, Sabbe BGC: Antidepressants and the risk of hyponatremia: a class-byclass review of literature. Psychosomatics 2014;55:536-547.

112 Degner D, Grohmann R, Kropp S, Rüther E, Bender S, Engel RR, Schmidt LG: Severe adverse drug reactions of antidepressants: results of the German multicenter drug surveillance program AMSP. Pharmacopsychiatry 2004;37(suppl 1):S39-S45.

113 Coupland C, Dhiman P, Morriss R, Arthur A, Barton G, Hippisley-Cox J: Antidepressant use and risk of adverse outcomes in older people: population based cohort study. BMJ 2011;343:d4551.

114 Letmaier M, Painold A, Holl AK, Vergin H Engel R, Konstantinidis A, Kasper S, Grohmann R: Hyponatraemia during psychopharmacological treatment: results of a drug surveillance programme. Int J Neuropsychopharmacol 2012;15:739-748.

115 Jacob S: Hyponatremia associated with selective serotonin-reuptake inhibitors in older adults. Ann Pharmacother 2006;40:16181622. 
116 Eom CS, Lee HK, Ye S, Park SM, Cho KH: Use of selective serotonin reuptake inhibitors and risk of fracture: a systematic review and meta-analysis. J Bone Miner Res 2012; 27:1186-1195.

117 Stubbs B, Brefka S, Dallmeier D, Stubbs J, Vancampfort D, Denkinger MD: Depression and reduced bone mineral density at the hip and lumbar spine: a comparative metaanalysis of studies in adults 60 years and older. Psychosom Med 2016;78:492-500.

118 Rosenblat JD, Gregory JM, Carvalho AF, McIntyre RS: Depression and disturbed bone metabolism: a narrative review of the epidemiological findings and postulated mechanisms. Curr Mol Med 2016;16:165178.

119 Cizza G, Primma S, Csako G: Depression as a risk factor for osteoporosis. Trends Endocrinol Metab 2009;20:367-373.

$120 \mathrm{Wu}$ Q, Bencaz AF, Hentz JG, Crowell MD: Selective serotonin reuptake inhibitor treatment and risk of fractures: a meta-analysis of cohort and case-control studies. Osteoporos Int 2012;23:365-375.

121 Vestergaard P, Rejnmark L, Mosekilde L: Selective serotonin reuptake inhibitors and other antidepressants and risk of fracture. Calcif Tissue Int 2008;82:92-101.

122 Andrade C, Sandarsh S, Chethan KB, Nagesh KS: Serotonin reuptake inhibitor antidepressants and abnormal bleeding: a review for clinicians and a reconsideration of mechanisms. J Clin Psychiatry 2010;71:15651575.

123 Pai VB, Kelly MW: Bruising associated with the use of fluoxetine. Ann Pharmacother 1996;30:786-788.

124 de Abajo FJ: Effects of selective serotonin reuptake inhibitors on platelet function: mechanisms, clinical outcomes and implications for use in elderly patients. Drugs Aging 2011;28:345-367.

125 Halperin D, Reber G: Influence of antidepressants on hemostasis. Dialogues Clin Neurosci 2007;9:47-59.

126 Morriss R: Antidepressants are associated with hospital admitted intracranial bleeds in people taking other medication associated with bleeding. Evid Based Ment Health 2016;19:24.

127 Jiang HY, Chen HZ, Hu XJ, Yu ZH, Yang W, Deng M, Zhang YH, Ruan B: Use of selective serotonin reuptake inhibitors and risk of upper gastrointestinal bleeding: a systematic review and meta-analysis. Clin Gastroenterol Hepatol 2015; 13:42-50.e43.

128 Anglin R, Yuan Y, Moayyedi P, Tse F, Armstrong D, Leontiadis GI: Risk of upper gastrointestinal bleeding with selective serotonin reuptake inhibitors with or without concurrent nonsteroidal anti-inflammatory use: a systematic review and meta-analysis. Am J Gastroenterol 2014;109:811-819.
129 Perahia DG, Bangs ME, Zhang Q, Cheng Y, Ahl J, Frakes EP, Adams MJ, Martinez JM: The risk of bleeding with duloxetine treatment in patients who use nonsteroidal antiinflammatory drugs (NSAIDs): analysis of placebo-controlled trials and post-marketing adverse event reports. Drug Healthc $\mathrm{Pa}$ tient Saf 2013;5:211-219.

130 de Abajo FJ, García-Rodríguez LA: Risk of upper gastrointestinal tract bleeding associated with selective serotonin reuptake inhibitors and venlafaxine therapy: interaction with nonsteroidal anti-inflammatory drugs and effect of acid-suppressing agents. Arch Gen Psychiatry 2008;65:795-803.

131 Cheng YL, Hu HY, Lin XH, Luo JC, Peng YL, Hou MC, Lin HC, Lee FY: Use of SSRI, but not SNRI, increased upper and lower gastrointestinal bleeding: a nationwide population-based cohort study in Taiwan. Medicine (Baltimore) 2015;94:e2022.

132 Targownik LE, Bolton JM, Metge CJ, Leung $S$, Sareen J: Selective serotonin reuptake inhibitors are associated with a modest increase in the risk of upper gastrointestinal bleeding. Am J Gastroenterol 2009;104: 1475-1482.

133 Paton C, Ferrier IN: SSRIS and gastrointestinal bleeding. BMJ 2005;331:529-530.

134 Haddad PM, Dursun SM: Neurological complications of psychiatric drugs: clinical features and management. Hum Psychopharmacol 2008;23(suppl 1):15-26.

135 Hawthorne JM, Caley CF: Extrapyramidal reactions associated with serotonergic antidepressants. Ann Pharmacother 2015;49: 1136-1152.

136 Leo RJ: Movement disorders associated with the serotonin selective reuptake inhibitors. J Clin Psychiatry 1996;57:449-454.

137 Schillevoort I, van Puijenbroek EP, de Boer A, Roos RAC, Jansen PAF, Leufkens HGM: Extrapyramidal syndromes associated with selective serotonin reuptake inhibitors: a case-control study using spontaneous reports. Int Clin Psychopharmacol 2002;17: $75-79$.

138 Gill HS, DeVane CL, Risch SC: Extrapyramidal symptoms associated with cyclic antidepressant treatment: a review of the literature and consolidating hypotheses. J Clin Psychopharmacol 1997;17:377-389.

139 Meltzer HY, Young M, Metz J, Fang VS, Schyve PM, Arora RC: Extrapyramidal side effects and increased serum prolactin following fluoxetine, a new antidepressant. J Neural Transm 1979;45:165-175.

140 Madhusoodanan S, Alexeenko L, Sanders R, Brenner R: Extrapyramidal symptoms associated with antidepressants - a review of the literature and an analysis of spontaneous reports. Ann Clin Psychiatry 2010;22:148156.
141 Hedenmalm K, Güzey C, Dahl M-L, Yue Q-Y, Spigset O: Risk factors for extrapyramidal symptoms during treatment with selective serotonin reuptake inhibitors, including cytochrome P-450 enzyme, and serotonin and dopamine transporter and receptor polymorphisms. J Clin Psychopharmacol 2006;26:192-197.

142 Konstantakopoulos G, Kouzoupis AV, Papageorgiou SG, Oulis P: Putative neuroleptic malignant syndrome associated with sertraline withdrawal. J Clin Psychopharmacol 2009;29:300-301.

143 Boyer EW, Shannon M: The serotonin syndrome. N Engl J Med 2005;352:1112-1120.

144 Iqbal MM, Basil MJ, Kaplan J, Iqbal MT: Overview of serotonin syndrome. Ann Clin Psychiatry 2012;24:310-318.

145 Isbister GK, Bowe SJ, Dawson A, Whyte IM: Relative toxicity of selective serotonin reuptake inhibitors (SSRIs) in overdose. J Toxicol Clin Toxicol 2004;42:277-285.

146 Brvar M, Stajer D, Kozelj G, Osredkar J, Mozina M, Bunc M: Urinary serotonin level is associated with serotonin syndrome after moclobemide, sertraline, and citalopram overdose. Clin Toxicol (Phila) 2007;45:458460.

147 Bortolato B, Miskowiak KW, Kohler CA, Maes M, Fernandes BS, Berk M, Carvalho AF: Cognitive remission: a novel objective for the treatment of major depression? BMC Med 2016;14:9.

148 Rosenblat JD, Kakar R, McIntyre RS: The cognitive effects of antidepressants in major depressive disorder: a systematic review and meta-analysis of randomized clinical trials. Int J Neuropsychopharmacol 2015; 19:pyv082.

149 Bortolato B, Carvalho AF, McIntyre RS Cognitive dysfunction in major depressive disorder: a state-of-the-art clinical review. CNS Neurol Disord Drug Targets 2014;13: 1804-1818.

150 Wroolie TE, Williams KE, Keller J, Zappert LN, Shelton SD, Kenna HA, Reynolds MF, Rasgon NL: Mood and neuropsychological changes in women with midlife depression treated with escitalopram. J Clin Psychopharmacol 2006;26:361-366.

151 Fava M, Graves LM, Benazzi F, Scalia MJ, Iosifescu DV, Alpert JE, Papakostas GI: A cross-sectional study of the prevalence of cognitive and physical symptoms during long-term antidepressant treatment. J Clin Psychiatry 2006;67:1754-1759.

152 Anderson HD, Pace WD, Libby AM, West DR, Valuck RJ: Rates of 5 common antidepressant side effects among new adult and adolescent cases of depression: a retrospective US claims study. Clin Ther 2012;34: 113-123.

153 Shin D, Oh YH, Eom C-S, Park SM: Use of selective serotonin reuptake inhibitors and risk of stroke: a systematic review and metaanalysis. J Neurol 2014;261:686-695. 
154 Coupland C, Hill T, Morriss R, Moore M, Arthur A, Hippisley-Cox J: Antidepressant use and risk of cardiovascular outcomes in people aged 20-64: cohort study using primary care database. BMJ 2016;352:i1350.

155 Trindade E, Menon D, Topfer LA, Coloma C: Adverse effects associated with selective serotonin reuptake inhibitors and tricyclic antidepressants: a meta-analysis. CMAJ 1998;159:1245-1252.

156 Marcy TR, Britton ML: Antidepressant-induced sweating. Ann Pharmacother 2005; 39:748-752.

157 Cheshire WP, Fealey RD: Drug-induced hyperhidrosis and hypohidrosis: incidence, prevention and management. Drug Saf 2008;31:109-126.

158 Ashton AK, Weinstein WL: Cyproheptadine for drug-induced sweating. Am J Psychiatry 2002;159:874-875.

159 Lauer CJ, Schreiber W, Holsboer F, Krieg JC: In quest of identifying vulnerability markers for psychiatric disorders by all-night polysomnography. Arch Gen Psychiatry 1995; 52:145-153.

160 Arfken CL, Joseph A, Sandhu GR, Roehrs T, Douglass AB, Boutros NN: The status of sleep abnormalities as a diagnostic test for major depressive disorder. J Affect Disord 2014;156:36-45.

161 Wilson S, Argyropoulos S: Antidepressants and sleep: a qualitative review of the literature. Drugs 2005;65:927-947.

162 Tribl GG, Wetter TC, Schredl M: Dreaming under antidepressants: a systematic review on evidence in depressive patients and healthy volunteers. Sleep Med Rev 2013;17: 133-142.

163 Rottach KG, Schaner BM, Kirch MH, Zivotofsky AZ, Teufel LM, Gallwitz T, Messer T: Restless legs syndrome as side effect of second generation antidepressants. J Psychiatr Res 2008;43:70-75.

164 Salín-Pascual RJ, Galicia-Polo L, DruckerColín R: Sleep changes after 4 consecutive days of venlafaxine administration in normal volunteers. J Clin Psychiatry 1997;58: 348-350.

165 Bayard M, Bailey B, Acharya D, Ambreen F, Duggal S, Kaur T, Rahman ZU, Roller K, Tudiver F: Bupropion and restless legs syndrome: a randomized controlled trial. J Am Board Fam Med 2011;24:422-428.

166 Price J, Cole V, Goodwin GM: Emotional side-effects of selective serotonin reuptake inhibitors: qualitative study. Br J Psychiatry 2009; 195:211-217.

167 Szmulewicz A, Samame C, Caravotta P, Martino DJ, Igoa A, Hidalgo-Mazzei D, Colom F, Strejilevich SA: Behavioral and emotional adverse events of drugs frequently used in the treatment of bipolar disorders: clinical and theoretical implications. Int $\mathrm{J} \mathrm{Bi}$ polar Disord 2016;4:6.
168 Levy R, Dubois B: Apathy and the functional anatomy of the prefrontal cortex-basal ganglia circuits. Cereb Cortex 2006;16:916928.

169 Tondo L, Vazquez G, Baldessarini RJ: Mania associated with antidepressant treatment: comprehensive meta-analytic review. Acta Psychiatr Scand 2010;121:404-414.

170 Sani G, Napoletano F, Vohringer PA, Sullivan M, Simonetti A, Koukopoulos A, Danese E, Girardi P, Ghaemi N: Mixed depression: clinical features and predictors of its onset associated with antidepressant use. Psychother Psychosom 2014;83:213-221.

171 Offidani E, Fava GA, Tomba E, Baldessarini RJ: Excessive mood elevation and behavioral activation with antidepressant treatment of juvenile depressive and anxiety disorders: a systematic review. Psychother Psychosom 2013;82:132-141.

172 Harada T, Sakamoto K, Ishigooka J: Incidence and predictors of activation syndrome induced by antidepressants. Depress Anxiety $2008 ; 25: 1014-1019$.

173 Fava GA: Rational use of antidepressant drugs. Psychother Psychosom 2014;83:197204.

174 Cusin C, Fava M, Amsterdam JD, Quitkin FM, Reimherr FW, Beasley CM Jr, Rosenbaum JF, Perlis RH: Early symptomatic worsening during treatment with fluoxetine in major depressive disorder: prevalence and implications. J Clin Psychiatry 2007;68:5257.

175 Harvey AT, Silkey BS, Kornstein SG, Clary CM: Acute worsening of chronic depression during a double-blind, randomized clinical trial of antidepressant efficacy: differences by sex and menopausal status. J Clin Psychiatry 2007;68:951-958.

176 Pozzi M, Radice S, Clementi E, Molteni M, Nobile M: Antidepressants and, suicide and self-injury: causal or casual association? Int J Psychiatry Clin Pract 2016;20:47-51.

177 Leon AC, Fiedorowicz JG, Solomon DA, Li C, Coryell WH, Endicott J, Fawcett J, Keller MB: Risk of suicidal behavior with antidepressants in bipolar and unipolar disorders. J Clin Psychiatry 2014;75:720-727.

178 Baldessarini RJ, Tondo L, Strombom IM, Dominguez S, Fawcett J, Licinio J, Oquendo MA, Tollefson GD, Valuck RJ, Tohen M: Ecological studies of antidepressant treatment and suicidal risks. Harv Rev Psychiatry 2007;15:133-145.

179 Stone MB: The FDA warning on antidepressants and suicidality - why the controversy? N Engl J Med 2014;371:1668-1671.

180 Braun C, Bschor T, Franklin J, Baethge C: Suicides and suicide attempts during longterm treatment with antidepressants: a meta-analysis of 29 placebo-controlled studies including 6,934 patients with major depressive disorder. Psychother Psychosom 2016; 85:171-179.
181 Teicher MH, Glod C, Cole JO: Emergence of intense suicidal preoccupation during fluoxetine treatment. Am J Psychiatry 1990;147: 207-210.

182 Henry A, Kisicki MD, Varley C: Efficacy and safety of antidepressant drug treatment in children and adolescents. Mol Psychiatry 2012;17:1186-1193

183 Sharma T, Guski LS, Freund N, Gøtzsche PC: Suicidality and aggression during antidepressant treatment: systematic review and meta-analyses based on clinical study reports. BMJ 2016;352:165.

184 Miller M, Swanson SA, Azrael D, Pate V, Stürmer T: Antidepressant dose, age, and the risk of deliberate self-harm. JAMA Intern Med 2014;174:899-909.

185 Wasserman D, Rihmer Z, Rujescu D, Sarchiapone M, Sokolowski M, Titelman D, Zalsman G, Zemishlany Z, Carli V, Association EP: The European Psychiatric Association (EPA) guidance on suicide treatment and prevention. Eur Psychiatry 2012;27: 129-141.

186 Turecki G, Brent DA: Suicide and suicidal behaviour. Lancet 2016;387:1227-1239.

187 Hawton K, Bergen H, Simkin S, Cooper J, Waters K, Gunnell D, Kapur N: Toxicity of antidepressants: rates of suicide relative to prescribing and non-fatal overdose. Br J Psychiatry 2010;196:354-358.

188 White NC, Litovitz T, Clancy C: Suicidal antidepressant overdoses: a comparative analysis by antidepressant type. J Med Toxicol 2008;4:238-250.

189 Wilson E, Lader M: A review of the management of antidepressant discontinuation symptoms. Ther Adv Psychopharmacol 2015;5:357-368.

190 Fava GA, Gatti A, Belaise C, Guidi J, Offidani E: Withdrawal symptoms after selective serotonin reuptake inhibitor discontinuation: a systematic review. Psychother Psychosom 2015;84:72-81.

191 Starcevic V, Brakoulias V, Viswasam K, Berle $\mathrm{D}$ : Inconsistent portrayal of medication dependence, withdrawal and discontinuation symptoms in treatment guidelines for anxiety disorders. Psychother Psychosom 2015;84:379-380.

192 Chouinard G, Chouinard VA: New classification of selective serotonin reuptake inhibitor withdrawal. Psychother Psychosom 2015;84:63-71.

193 Narayan V, Haddad PM: Antidepressant discontinuation manic states: a critical review of the literature and suggested diagnostic criteria. J Psychopharmacol 2011;25:306313.

194 Harvey BH, Slabbert FN: New insights on the antidepressant discontinuation syndrome. Hum Psychopharmacol 2014;29: 503-516. 
195 Belaise C, Gatti A, Chouinard VA, Chouinard G: Persistent post-withdrawal disorders induced by paroxetine, a selective serotonin reuptake inhibitor, and treated with specific cognitive behavioral therapy. Psychother Psychosom 2014;83:247-248.

196 Preskorn SH: Comparison of the tolerability of bupropion, fluoxetine, imipramine, nefazodone, paroxetine, sertraline, and venlafaxine. J Clin Psychiatry 1995;56(suppl 6):12-21.

197 Trindade E, Menon D, Topfer LA, Coloma C: Adverse effects associated with selective serotonin reuptake inhibitors and tricyclic antidepressants: a meta-analysis. CMAJ 1998;159:1245-1252.

198 Costagliola C, Parmeggiani F, Sebastiani A: SSRIs and intraocular pressure modifications: evidence, therapeutic implications and possible mechanisms. CNS Drugs 2004; 18:475-484.

199 Ezra DG, Storoni M, Whitefield LA: Simultaneous bilateral acute angle closure glaucoma following venlafaxine treatment. Eye (Lond) 2006;20:128-129.

200 Ng B, Sanbrook GM, Malouf AJ, Agarwal SA: Venlafaxine and bilateral acute angle closure glaucoma. Med J Aust 2002;176:241.

201 Symes RJ, Etminan M, Mikelberg FS: Risk of angle-closure glaucoma with bupropion and topiramate. JAMA Ophthalmol 2015;133: 1187-1189.

202 Chen HY, Lin CL, Kao CH: Long-term use of selective serotonin reuptake inhibitors and risk of glaucoma in depression patients. Medicine (Baltimore) 2015;94:e2041.

203 Chen HY, Lin CL, Lai SW, Kao CH: Association of selective serotonin reuptake inhibitor use and acute angle-closure glaucoma. J Clin Psychiatry 2016, Epub ahead of print.

204 Richa S, Yazbek JC: Ocular adverse effects of common psychotropic agents: a review. CNS Drugs 2010;24:501-526.

205 Etminan M, Mikelberg FS, Brophy JM: Selective serotonin reuptake inhibitors and the risk of cataracts: a nested case-control study. Ophthalmology 2010;117:1251-1255.

206 Erie JC, Brue SM, Chamberlain AM, Hodge DO: Selective serotonin reuptake inhibitor use and increased risk of cataract surgery: a population-based, case-control study. Am J Ophthalmol 2014;158:192-197.e191.

207 Rittenhouse PA, Levy AD, Li Q, Bethea CL, Van de Kar LD: Neurons in the hypothalamic paraventricular nucleus mediate the serotonergic stimulation of prolactin secretion via 5-HT1c/2 receptors. Endocrinology 1993;133:661-667.

208 Trenque T, Herlem E, Auriche P, Drame M: Serotonin reuptake inhibitors and hyperprolactinaemia: a case/non-case study in the French pharmacovigilance database. Drug Saf 2011;34:1161-1166.

209 Ajmal A, Joffe H, Nachtigall LB: Psychotropic-induced hyperprolactinemia: a clinical review. Psychosomatics 2014;55:29-36.
210 Mondal S, Saha I, Das S, Ganguly A, Das D, Tripathi SK: A new logical insight and putative mechanism behind fluoxetine-induced amenorrhea, hyperprolactinemia and galactorrhea in a case series. Ther Adv Psychopharmacol 2013;3:322-334.

211 Mahasuar R, Majhi P, Ravan JR: Euprolactinemic galactorrhea associated with use of imipramine and escitalopram in a postmenopausal woman. Gen Hosp Psychiatry 2010;32:341.e311-e343.

212 Praharaj SK: Euprolactinemic galactorrhea with escitalopram. J Neuropsychiatry Clin Neurosci 2014;26:E25-E26.

213 Bennett HA, Einarson A, Taddio A, Koren G, Einarson TR: Prevalence of depression during pregnancy: systematic review. Obstet Gynecol 2004;103:698-709.

214 Grigoriadis S, VonderPorten EH, Mamisashvili L, Tomlinson G, Dennis C-L, Koren G, Steiner M, Mousmanis P, Cheung A, Radford K, Martinovic J, Ross LE: The impact of maternal depression during pregnancy on perinatal outcomes: a systematic review and meta-analysis. J Clin Psychiatry 2013; 74:e321-e341.

215 Larsen ER, Damkier P, Pedersen LH, FengerGron J, Mikkelsen RL, Nielsen RE, Linde VJ, Knudsen HED, Skaarup L, Videbech P: Use of psychotropic drugs during pregnancy and breast-feeding. Acta Psychiatr Scand 2015; 132:1-28.

216 Reis M, Källén B: Combined use of selective serotonin reuptake inhibitors and sedatives/ hypnotics during pregnancy: risk of relatively severe congenital malformations or cardiac defects: a register study. BMJ Open 2013;3:e002166.

217 Grigoriadis S, VonderPorten EH, Mamisashvili L, Roerecke M, Rehm J, Dennis CL, Koren G, Steiner M, Mousmanis P, Cheung A, Ross LE: Antidepressant exposure during pregnancy and congenital malformations: is there an association? A systematic review and meta-analysis of the best evidence. J Clin Psychiatry 2013;74:e293-e308.

218 Palmsten K, Hernández-Díaz S, Huybrechts KF, Williams PL, Michels KB, Achtyes ED, Mogun H, Setoguchi S: Use of antidepressants near delivery and risk of postpartum hemorrhage: cohort study of low income women in the United States. BMJ 2013; 347:f4877.

219 Reefhuis J, Devine O, Friedman JM, Louik C, Honein MA; Study NBDP: Specific SSRIs and birth defects: Bayesian analysis to interpret new data in the context of previous reports. BMJ 2015;351:h3190.

220 Grigoriadis S, Vonderporten EH, Mamisashvili L, Tomlinson G, Dennis CL, Koren G, Steiner M, Mousmanis P, Cheung A, Ross LE: Prenatal exposure to antidepressants and persistent pulmonary hypertension of the newborn: systematic review and metaanalysis. BMJ 2014;348:f6932.
221 Hudson JI, Wohlreich MM, Kajdasz DK, Mallinckrodt $\mathrm{CH}$, Watkin JG, Martynov OV: Safety and tolerability of duloxetine in the treatment of major depressive disorder: analysis of pooled data from eight placebocontrolled clinical trials. Hum Psychopharmacol 2005;20:327-341.

222 Furu K, Kieler H, Haglund B, Engeland A, Selmer R, Stephansson O, Valdimarsdottir UA, Zoega H, Artama M, Gissler M, Malm $H$, Nørgaard M: Selective serotonin reuptake inhibitors and venlafaxine in early pregnancy and risk of birth defects: population based cohort study and sibling design. BMJ 2015;350:h1798.

223 Bellantuono C, Vargas M, Mandarelli G, Nardi B, Martini MG: The safety of serotonin-noradrenaline reuptake inhibitors (SNRIs) in pregnancy and breastfeeding: a comprehensive review. Hum Psychopharmacol 2015;30:143-151.

224 Chun-Fai-Chan B, Koren G, Fayez I, Kalra S, Voyer-Lavigne S, Boshier A, Shakir S, Einarson A: Pregnancy outcome of women exposed to bupropion during pregnancy: a prospective comparative study. Am J Obstet Gynecol 2005;192:932-936.

225 Alwan S, Reefhuis J, Botto LD, Rasmussen SA, Correa A, Friedman JM; National Birth Defects Prevention Study: Maternal use of bupropion and risk for congenital heart defects. Am J Obstet Gynecol 2010;203:52. e1-6.

226 Djulus J, Koren G, Einarson TR, Wilton L, Shakir S, Diav-Citrin O, Kennedy D, Voyer Lavigne S, De Santis M, Einarson A: Exposure to mirtazapine during pregnancy: a prospective, comparative study of birth outcomes. J Clin Psychiatry 2006;67:12801284.

227 Einarson A, Bonari L, Voyer-Lavigne S, Addis A, Matsui D, Johnson Y, Koren G: A multicentre prospective controlled study to determine the safety of trazodone and nefazodone use during pregnancy. Can J Psychiatry 2003;48:106-110

228 Ewing G, Tatarchuk Y, Appleby D, Schwartz N, Kim D: Placental transfer of antidepressant medications: implications for postnatal adaptation syndrome. Clin Pharmacokinet 2015;54:359-370.

229 Sanz EJ, De-las-Cuevas C, Kiuru A, Bate A, Edwards R: Selective serotonin reuptake inhibitors in pregnant women and neonatal withdrawal syndrome: a database analysis. Lancet (London) 2005;365:482-487.

230 Boucher N, Koren G, Beaulac-Baillargeon L: Maternal use of venlafaxine near term: correlation between neonatal effects and plasma concentrations. Ther Drug Monit 2009; 31:404-409.

231 Eberhard-Gran M, Eskild A, Opjordsmoen S: Use of psychotropic medications in treating mood disorders during lactation: practical recommendations. CNS Drugs 2006;20: 187-198. 
232 Brandes LJ, Arron RJ, Bogdanovic RP, Tong J, Zaborniak CL, Hogg GR, Warrington RC, Fang W, LaBella FS: Stimulation of malignant growth in rodents by antidepressant drugs at clinically relevant doses. Cancer Res 1992;52:3796-3800.

233 Bendele RA, Adams ER, Hoffman WP, Gries CL, Morton DM: Carcinogenicity studies of fluoxetine hydrochloride in rats and mice. Cancer Res 1992;52:6931-6935.

234 Gil-Ad I, Zolokov A, Lomnitski L, Taler M, Bar M, Luria D, Ram E, Weizman A: Evaluation of the potential anti-cancer activity of the antidepressant sertraline in human colon cancer cell lines and in colorectal cancerxenografted mice. Int J Oncol 2008;33:277286.

235 Abdul M, Logothetis CJ, Hoosein NM: Growth-inhibitory effects of serotonin uptake inhibitors on human prostate carcinoma cell lines. J Urol 1995;154:247-250.

236 Cosgrove L, Shi L, Creasey DE, Anaya-McKivergan M, Myers JA, Huybrechts KF: Antidepressants and breast and ovarian cancer risk: a review of the literature and researchers' financial associations with industry. PLoS One 2011;6:e18210.

237 Eom CS, Park SM, Cho KH: Use of antidepressants and the risk of breast cancer: a meta-analysis. Breast Cancer Res Treat 2012; 136:635-645.
238 Carvalho AF, Hyphantis T, Sales PMG, Soeiro-de-Souza MG, Macêdo DS, Cha DS, McIntyre RS, Pavlidis N: Major depressive disorder in breast cancer: a critical systematic review of pharmacological and psychotherapeutic clinical trials. Cancer Treat Rev 2014;40:349-355.

239 Ghaemi NS, Vohringer PA, Whitham EA: Antidepressants from a public health perspective: Re-examining effectiveness, suicide, and carcinogenicity. Acta Psychiatr Scand 2013;127:89-93.

240 Pae CU: Association between antidepressants and breast/ovarian cancer. Expert Opin Pharmacother 2012;13:441-444.

241 Froes Brandao D, Strasser-Weippl K, Goss PE: Prolactin and breast cancer: the need to avoid undertreatment of serious psychiatric illnesses in breast cancer patients: a review. Cancer 2016;122:184-188.

242 Rubin RR, Ma Y, Marrero DG, Peyrot M, Barrett-Connor EL, Kahn SE, Haffner SM, Price DW, Knowler WC: Elevated depression symptoms, antidepressant medicine use, and risk of developing diabetes during the diabetes prevention program. Diabetes Care 2008:31:420-426.

243 Ziere G, Dieleman JP, van der Cammen TJ, Hofman A, Pols HA, Stricker BH: Selective serotonin reuptake inhibiting antidepressants are associated with an increased risk of nonvertebral fractures. J Clin Psychopharmacol 2008;28:411-417.
244 Fava GA, Tomba E, Tossani E: Innovative trends in the design of therapeutic trials in psychopharmacology and psychotherapy. Prog Neuropsychopharmacol Biol Psychiatry 2013;40:306-311.

245 Fava G, Cosci F, Tomba E: Iatrogenic comorbidity in mental health. Psychother Psychosom 2015;84(suppl 1):22.

246 Karch FE, Lasagna L: Adverse drug reactions: a critical review. JAMA 1975;234. 1236-1241.

247 Kaymaz N, van Os J, Loonen AJ, Nolen WA: Evidence that patients with single versus recurrent depressive episodes are differentially sensitive to treatment discontinuation: a meta-analysis of placebo-controlled randomized trials. J Clin Psychiatry 2008;69: 1423-1436.

248 Guidi J, Tomba E, Fava GA: The sequential integration of pharmacotherapy and psychotherapy in the treatment of major depressive disorder: a meta-analysis of the sequential model and a critical review of the literature. Am J Psychiatry 2016;173:128137.

249 Fava GA, Guidi J, Rafanelli C, Sonino N: The clinical inadequacy of evidence-based medicine and the need for a conceptual framework based on clinical judgment. Psychother Psychosom 2015;84:1-3. 